\title{
Sources of error in picture naming under time pressure
}

\author{
Toby J. Lloyd-Jones ANd MANDY NetTlemill \\ University of Wales Swansea, Swansea, Wales
}

\begin{abstract}
We used a deadline procedure to investigate how time pressure may influence the processes involved in picture naming. The deadline exaggerated errors found under naming without deadline. There were also category differences in performance between living and nonliving things and, in particular, for animals versus fruit and vegetables. The majority of errors were visually and semantically related to the target (e.g., celery-asparagus), and there was a greater proportion of these errors made to living things. Importantly, there were also more visual-semantic errors to animals than to fruit and vegetables. In addition, there were a smaller number of pure semantic errors (e.g., nut-bolt), which were made predominantly to nonliving things. The different kinds of error were correlated with different variables. Overall, visual-semantic errors were associated with visual complexity and visual similarity, whereas pure semantic errors were associated with imageability and age of acquisition. However, for animals, visual-semantic errors were associated with visual complexity, whereas for fruit and vegetables they were associated with visual similarity. We discuss these findings in terms of theories of category-specific semantic impairment and models of picture naming.
\end{abstract}

We investigated how time pressure may influence the processes involved in picture naming. Timed picture naming is a widely used technique for the study of lexical access, and both timed and untimed picture naming have been widely used in studies of brain-injured patients (for reviews, see Bates et al., 2003; Glaser, 1992; Gordon, 1997; Johnson, Paivio, \& Clark, 1996). As a consequence, the representations and processes mediating picture naming are relatively well understood. Naming a common object requires access to, and retrieval of, at least three kinds of stored representations. Visual input is matched to a stored visual representation of object shape. Accessing this stored visual representation enables further access to a semantic representation (comprising categorical, functional, and associative information), which provides the basis for recognition. In order to name a visually presented object, the object name is subsequently retrieved. ${ }^{1}$ Nevertheless, what happens to processing when the system is placed under time pressure?

In naming to deadline, participants have to respond before they are ready, resulting in various kinds of errors (Vitkovitch \& Humphreys, 1991; Vitkovitch, Humphreys, \& Lloyd-Jones, 1993). The nature of these errors varies according to the visual similarity of the object. In particular, a wider range of visual and within-category semantic naming errors (visual-semantic errors, such as naming a giraffe as zebra) were made to objects determined, a priori, to be from visually similar categories, as compared with those from visually dissimilar categories. Vitkovitch et al. argued that this is because objects from visually similar categories activate a broader set of visually related objects than do items from visually dissimilar categories. For visually similar objects, the early visual stages of processing are time consuming and, possibly, unresolved under deadline conditions; hence, the system is noisier, and visually based errors predominate. Furthermore, according to this account, because information transmission is continuously fed forward through the system, the effects of visual similarity can have consequences for subsequent semantic processing, increasing noise and the probability of error at that stage as well. In essence, because of the coactivation of a number of competing visual representations, a number of semantic representations of items that are visually similar also become activated (mainly, items from the same category, but also visually similar items that are not semantically related). Thus, Vitkovitch et al. argued that such errors reflect a combination of competition at visual and semantic stages of processing. In contrast, more pure semantic errors (such as naming a nut as bolt) were made to objects from categories with fewer visually similar members. It is argued that this is because visual processing is generally more efficient for visually dissimilar objects than for visually similar objects, and so the same response deadline is more likely to interrupt semantic, rather than visual, processing for this class of items.

We developed this research in light of recent evidence in the neuropsychological literature for category-specific semantic deficits - in particular, for selective impairments to the categories of animals (e.g., animals, birds, and insects), fruit and vegetables, and nonliving things (for a

T. J. Lloyd-Jones, t.j.lloyd-jones@swansea.ac.uk 
review, see Capitani, Laiacona, Mahon, \& Caramazza, 2003). Our premise was that some category-specific semantic deficits may reflect an exaggeration of processing difficulties that exist under normal circumstances (e.g., Humphreys, Riddoch, \& Quinlan, 1988; Lloyd-Jones \& Humphreys, 1997a, 1997b; Lloyd-Jones \& Luckhurst, $2002 \mathrm{~b}$ ). We examined, therefore, whether the pattern of performance under deadline naming reflects this tripartite distinction and, if so, whether the performance arises due to the organization of the system or statistical regularities in the distribution of properties of items in each of the categories-properties that are relevant to picture naming, including visual complexity, visual similarity, age of acquisition, and name frequency. An alternative outcome was that the findings might reflect only a binary living/nonliving distinction. We interpret our findings in terms of a number of theories of category-specific deficits, including the hierarchical interactive theory (HIT) of Humphreys and Forde (2001), which represents a recent development of the original Vitkovitch et al. (1993) account of deadline naming (see also Humphreys, Lamote, \& Lloyd-Jones, 1995).

\section{Category-Specific Semantic Deficits}

It is well established that neurologically impaired individuals may show selective difficulties in the recognition and naming of living or, less frequently, nonliving things (e.g., Farah, McMullen, \& Meyer, 1991; Hillis \& Caramazza, 1991; Sartori, Job, \& Coltheart, 1993; Silveri \& Gainotti, 1988; and many others). More recently, reviews of the neuropsychological literature have suggested a further subdivision, with selective difficulties in processing either animals (e.g., animals, birds, and insects) or fruit and vegetables (Capitani et al., 2003; Caramazza \& Mahon, 2003; Cree \& McRae, 2003). However, the interpretation of category-specific deficits remains controversial.

In general, theorists assume that the semantic system is made up of distinct visual, semantic, and lexical representations, which operate in an interactive fashion (e.g., Cree \& McRae, 2003; Humphreys \& Forde, 2001; and peer commentary). However, different theories have emphasized the importance of a number of different factors (see, e.g., the 2003 special issue of Cognitive Neuropsychology, Vol. 20, Nos. 3-6). Cree and McRae (2003, Table 1) have provided a useful taxonomy, which we will summarize briefly here. The main theories emphasize (1) the types of knowledge that comprise objects (e.g., sensory vs. functional knowledge-the sensory-functional [SF] account; Farah \& McClelland, 1991; Warrington \& Shallice, 1984; see also HIT, Humphreys \& Forde, 2001; recently, Cree \& McRae, 2003, have proposed 10 distinct knowledge types); (2) regularities in feature co-occurrence or distinguishing features among objects (the SF account; the organized unitary content hypothesis [OUCH], Caramazza, Hillis, Rapp, \& Romani, 1990; the conceptual structure [CS] account, Tyler \& Moss, 2001; the correlated and distinguishing features [CD] account, e.g., Gonnerman, Andersen, Devlin, Kempler, \& Seidenberg, 1997); (3) visual or semantic similarity among objects (HIT, OUCH, the CS account, and the CD account); (4) visual object complexity (e.g., Funnell \&
Sheridan, 1992); and (5) how often one encounters, hears, or reads about various objects (i.e., familiarity and name frequency; HIT; Warrington, 1975). Nevertheless, we note that some theorists have proposed multifactor accounts that incorporate many of these factors (Cree \& McRae, 2003; Humphreys \& Forde, 2001).

Theories may also be distinguished according to how they consider semantic knowledge to be represented: (1) in a single amodal store (OUCH, the CS account), (2) across sensory and functional systems (the SF account; see also HIT for a development of the SF account), or (3) across domain-specific semantic systems (Caramazza \& Shelton, 1998). The domain-specific hypothesis of Caramazza and Shelton proposes that evolutionary pressures have resulted in specialized and functionally dissociable neural systems dedicated to the domains of animals, fruit/ vegetables, conspecifics, and possibly tools.

This picture is further complicated by the fact that research on category differences in normal (nondeadline) picture processing has been mixed, with some studies showing a disadvantage for the recognizing and naming of living things (e.g., Humphreys et al., 1988; Lloyd-Jones \& Humphreys, 1997a, 1997b) and other studies showing a disadvantage for recognizing and naming nonliving things (Laws \& Gale, 2002; Laws \& Neve, 1999; Lloyd-Jones \& Luckhurst, 2002b). This is likely due to a number of factors, including confounding variables, the nature of the stimulus set, and the timing of stimulus presentation (Gerlach, 2001; Lloyd-Jones \& Luckhurst, 2002b). In this study, we provide converging evidence on the nature of observed category differences in performance by examining the pattern of association between the different kinds of errors and a set of variables known to influence picture naming. We now will turn to this line of research.

\section{Variables Influencing Picture Naming}

The influence of a number of variables on the latency and accuracy of normal picture naming has been examined in multiple regression studies (e.g., Barry, Morrison, \& Ellis, 1997; Snodgrass \& Yuditsky, 1996). However, several of these variables do not have a clear locus of effect (e.g., name agreement; Vitkovitch \& Tyrrell, 1995). Furthermore, some variables have not had robust effects (e.g., word length and familiarity; Barry et al., 1997). Finally, other variables have been shown to be important in parametric studies but have not received attention in multiple regression studies - for example, contour overlap (Humphreys et al., 1988) and visual part complexity (LloydJones \& Luckhurst, 2002a). We will focus here on six variables that we consider to be important determinants of picture naming: visual complexity, visual decomposability, visual similarity, imageability, age of acquisition, and name frequency. These variables will be described briefly below.

Visual complexity, visual decomposability, contour overlap. Effects of visual complexity have not been widely reported (for a review, see Johnson et al., 1996). For instance, some multiple regression studies have failed to show an effect of this particular variable on picture naming (Barry et al., 1997; Snodgrass \& Yuditsky, 1996). 
Nevertheless, Ellis and Morrison (1998) reported a positive finding, with increased complexity slowing naming. In contrast, parametric studies have suggested that visual complexity can influence performance, with increased complexity having a beneficial effect (Biederman, 1987; Lloyd-Jones \& Luckhurst, 2002a). In particular, LloydJones and Luckhurst (2002a) found an influence of visual complexity on response times (RTs) and accuracy in object decision and a fast classification decision for living/ nonliving things (which, it was argued, was based on visual features; cf. Snodgrass \& McCullough, 1986). They suggested a visual locus for the effects of complexity, and converging evidence for this conclusion has come from research on other kinds of object decision tasks (Carrasco \& Seamon, 1996) and on the effects of complexity on visual persistence (Long \& Wurst, 1984). Together, these studies suggest that increased visual complexity may have beneficial effects in retrieving some kind of stored visual object representation common to many objects (e.g., in object decision and other fast classification tasks; cf. Rosch, 1975; Snodgrass \& McCullough, 1986) but reduces the efficiency of performance when fine-grained visual differentiation between visual object representations is necessary, as in naming. It is also possible that null effects were observed in previous studies because of the measure of complexity that was selected. Most studies have used ratings obtained from Snodgrass and Vanderwart (1980), which involve a judgment of details or intricacy, whereas Lloyd-Jones and Luckhurst (2002a) and Biederman (1987) used a measure of decomposability (i.e., the number of nameable and nonnameable visual parts).

There is strong evidence that picture naming is influenced by the visual similarity of an object to other objects, where increased similarity is detrimental to naming time and accuracy (e.g., Humphreys et al., 1988; LloydJones \& Humphreys, 1997a, 1997b; for recent reviews, see Cree \& McRae, 2003; Humphreys \& Forde, 2001). A number of studies have used contour or image overlap of standardized pictures as a measure of this variable (e.g., Humphreys et al., 1988; Tranel, Logan, Frank, \& Damasio, 1997; although see Laws \& Gale, 2002), and it has been argued that visual similarity can influence both semantic and name retrieval, in addition to visual processing (e.g., Humphreys et al., 1988; Lloyd-Jones \& Humphreys, 1997a, 1997b; Vitkovitch et al., 1993).

Imageability. A key variable generally agreed to have its locus at a semantic stage of processing is imageability-namely, the extent to which a word's meaning has sensorimotor properties. Multiple regression studies have shown no effect on picture naming (Barry et al., 1997; Ellis \& Morrison, 1998). Nevertheless, using Lorch and Myers's (1990) alternative to the conventional regression procedure, Ellis and Morrison reported significant effects of this variable, with ease of imageability benefiting picture naming performance. In a parametric study, Morrison, Ellis, and Quinlan (1992) also failed to find an effect of imageability on picture naming, but their range of imageability values was restricted (Nickels, 1997, p. 39). However, in the word naming literature, Marcel and Patterson (1978) and Strain, Patterson, and Seidenberg (1995) found effects of imageability on word naming, and Plaut and Shallice (1993) interpreted imageability in their connectionist model of deep dyslexia in terms of the number of semantic features, or richness, of semantic representations. Nevertheless, we note that no study has assessed directly whether imageability may also influence the retrieval of visual object representations, and so this remains a possibility.

Age of acquisition and name frequency. A number of studies support age of acquisition and name frequency as important variables influencing picture naming (for a review, see Barry, Hirsh, Johnston, \& Williams, 2001). However, the relationship between the two variables and their locus of influence continue to be the subject of much debate. For instance, a number of researchers currently argue that age of acquisition influences semantic or lexical (phonological) processing (Barry et al., 2001; Ellis \& Lambon Ralph, 2000; Ellis \& Morrison, 1998; Ghyselinck, Custers, \& Brysbaert, 2004; Izura \& Ellis, 2004; Zevin \& Seidenberg, 2002; and a special issue of Visual Cognition, Vol. 13, Nos. 7-8). However, there is also some evidence that age of acquisition, but not name frequency, may influence object recognition, as assessed by object decision performance (Moore, Smith-Spark, \& Valentine, 2004).

In summary, it is clear that it can be difficult to make a one-to-one correspondence between the effects of a particular variable and a particular processing stage. Furthermore, the locus of a variable will depend on how information is transmitted through the system. In a system in which processing at a prior representational stage in some sense stops or is completed before processing of a subsequent representational stage begins, a variable may have its locus at a particular representational stage (e.g., Levelt, Roelofs, \& Meyer, 1999; Nickels, 1995; Schriefers, Meyer, \& Levelt, 1990). However, in a system in which information transmission is continuously fed forward and backward between representational stages, the effects of a particular variable may be felt throughout the system and may also influence one part of the system more than another (e.g., Humphreys \& Forde, 2001; Humphreys et al., 1995; Humphreys et al., 1988; Lloyd-Jones \& Humphreys, 1997a, 1997b; Vitkovitch et al., 1993). Therefore, we will focus here primarily on the overall pattern of influence of the different variables on different kinds of error.

\section{The Present Study}

We examined the effects of a deadline on the naming of living and nonliving things and, in particular, on the naming of animals (i.e., animals, birds, and insects) versus fruit and vegetables. Naming errors were classified using the procedure in Vitkovitch et al. (1993), and we expected the main error type to be visual-semantic errors (i.e., errors reflecting visual and semantic similarity to the target, such as naming a giraffe as zebra). We also expected a smaller number of pure semantic errors (i.e., errors reflecting only semantic similarity to the target, such as naming a nut as bolt).

The SF account of category-specific deficits advocated by Warrington and Shallice (1984) is considered by many to be the standard view against which other hypotheses 
are tested (for instance, see the chapters in Forde \& Humphreys, 2002). This account proposes that sensory information is primarily important for distinguishing among living things and functional information is primarily important for distinguishing among nonliving things (for recent evidence, see Garrard, Lambon Ralph, Hodges, \& Patterson, 2001; McRae \& Cree, 2002; but see also, e.g., Caramazza \& Shelton, 1998). On this account, we might expect a binary living/nonliving pattern of findings, with more visual-semantic errors to living things, because time pressure quickens and, consequently, degrades the processing of sensory information. Evidence of a tripartite distinction between categories would not be consistent with this account. However, a more recent account that also emphasizes the type of semantic knowledge that is important for different categories has been presented by Cree and McRae (2003). In a study with normal participants, they have shown that a theory based on differential ratios of nine distinct knowledge types can account for a tripartite distinction between animals, fruit and vegetables, and nonliving things. We assessed, therefore, whether a differential weighting of these distinct knowledge types would contribute to the findings of this study.

Nevertheless, as Cree and McRae (2003) acknowledged, this approach alone was unable to account for the fact that impairments for living things tend to occur much more frequently than they do for nonliving things. They suggest that further susceptibility factors contribute to the prevalence of different types of impairment.

Other approaches have also emphasized statistical regularities across concepts, stressing the importance of feature co-occurrence, distinguishing features, visual and semantic similarity among objects, visual object complexity, and how often one encounters information about particular objects (e.g., Gonnerman et al., 1997; Humphreys \& Forde, 2001; Tyler \& Moss, 2001). A common thread is that there is a correlation between how easy it is to differentiate the target object from competitors on a particular factor and object category (Humphreys, Riddoch, \& Forde, 2001; Lloyd-Jones \& Humphreys, 1997b). For instance, it has been argued that living things tend to be more visually or semantically similar (e.g., Gonnerman et al., 1997; Humphreys \& Forde, 2001) and tend to share more correlated features or fewer distinctive features (e.g., Caramazza et al., 1990; Tyler \& Moss, 2001). On this basis, we would expect more visual-semantic errors to living things and, possibly, more visual-semantic errors to animals than to fruit and vegetables, since concepts in these categories are not easily differentiated and a deadline will add to this difficulty. In the latter case, Cree and McRae (2003) have shown that in addition to other factors, the category they termed creatures (which includes animals, birds, and insects) is more visually complex (i.e., objects have more external components and surface properties) than is either fruit and vegetables or nonliving things. They suggest that this may be one reason why semantic impairments are more prevalent for creatures than they are for nonliving things. More visually complex objects will also have a greater number of spatial relations between component parts, which may reduce the efficiency of performance when fine-grained visual differentiation between visual object representations is necessary, as in picture naming (Lloyd-Jones \& Luckhurst, 2002a).

We also examined whether particular variables were important in the production of errors for different semantic categories. Our premise was that some category-specific deficits may reflect an exaggeration of the processing difficulties experienced under normal circumstances. If this is the case, we might expect that the same variables that slow performance under no-deadline conditions will also account for increased errors in the deadline condition. Second, according to theories that emphasize the importance of both distributional statistics across concepts and visual factors in category-specific deficits, we might expect visual variables such as visual complexity and visual similarity to be particularly important for naming living things (e.g., Arguin, 2002; Cree \& McRae, 2003; Dixon, Bub, \& Arguin, 1997; see HIT, Humphreys \& Forde, 2001). In contrast, it is also possible that variables associated more strongly with name retrieval, such as age of acquisition and name frequency, might be particularly important for naming nonliving things (e.g., Humphreys \& Forde, 2001; Humphreys et al., 1995; Humphreys et al., 1988). For instance, Humphreys et al. (1988; see also Snodgrass \& Yuditsky, 1996) found that in picture naming, effects of visual similarity varied with name frequency. In particular, high name frequency items were named more quickly than low name frequency items only for pictures that were of low, rather than high, visual similarity. On the whole, low visual similarity items were nonliving things. They argued that it is only when visual processing is relatively efficient that the effects of later-acting variables, such as name frequency and age of acquisition, may become apparent.

Finally, as we have suggested, visual complexity is likely to be a variable associated particularly with the category of animals (e.g., Cree \& McRae, 2003). In contrast, visual similarity is likely to be associated with the category of fruit and vegetables, particularly when diagnostic color cues are absent from the stimuli, as was the case here (e.g., Humphreys \& Forde, 2001; Lloyd-Jones \& Humphreys, 1997b; Vernon \& Lloyd-Jones, 2003). We also note that for two of the three studies in which a selective deficit for fruit and vegetables has been examined, the impairment was confined to name retrieval, which was placed under time pressure in the present study (Farah \& Wallace, 1992; Hart, Berndt, \& Caramazza, 1985; but see Samson \& Pillon, 2003).

\section{METHOD}

\section{Participants}

Thirty undergraduate and postgraduate students at the University of Kent performed the naming-without-deadline task. Fifteen were male, and 15 were female. The average age was 20 years. Thirty undergraduate and postgraduate students at the University of Birmingham performed the naming-with-deadline task. Fourteen were male, and 16 were female. The average age was 21 years. All the participants were monolingual English speakers with normal or corrected-to-normal visual acuity. 


\section{Stimuli and Apparatus}

Two hundred and four pictures were selected from the Snodgrass and Vanderwart (1980) corpus. They were pictures for which (1) there were clearly different semantic categories, as designated by Snodgrass and Vanderwart, which was necessary for obtaining ratings of contour overlap, and (2) ratings were available. We excluded pictures of musical instruments and body parts, since they have been found to be atypical of living and nonliving categories in the neuropsychological literature (e.g., Laiacona \& Capitani, 2001; Laws \& Neve, 1999; McKenna \& Warrington, 1978; Saffran \& Schwartz, 1994). There were five categories of living things (animals, birds, insects, fruit, and vegetables; 71 items in all) and nine categories of nonliving things (clothing, furniture, kitchen utensils, vehicles, weapons, buildings and parts, tools, household items, and toys; 133 items in all). For animals (i.e., animals, birds, and insects) there were 47 items in all, and for fruit and vegetables there were 24 items in all. The unequal number of categories comprising living and nonliving things reflects their proportions in the Snodgrass and Vanderwart corpus. Average category size was 14.2 items $(S D=9)$ for living things, and 15.1 items $(S D=7.2)$ for nonliving things. Snodgrass and Vanderwart pictures had been digitally scanned into MacPaint documents and touched up, using the MacPaint graphics package to ensure clear line drawings of clear contrast. Each picture was presented in the center of the screen. The participants sat a comfortable distance from the screen whereby the stimuli subtended a visual angle of approximately $6^{\circ}$. The stimuli were presented on a PowerMac 8200/120 computer using PsychLab software (Bub \& Gum, 1988). Errors were noted by the experimenter.

The selection of variables to be associated with performance was outlined in the introduction. Below, we will cite references supporting each measure and, where appropriate, the source from which they were obtained. The variables were complexity, decomposability, contour overlap, imageability, age of acquisition, and name frequency. It is important to note that if we include a number of other variables in the analyses that follow-namely, image agreement, name agreement, familiarity, and number of syllables - the general pattern of results and main findings for the main variables remain unaltered (see Appendix A). Note also that given the importance of the distinction between living and nonliving things and its potential correlation with the variables of interest, it was appropriate to include it in the analyses. Therefore, a dummy variable was constructed for living versus nonliving things (living things were given the value 0 , and nonliving things the value 1 ).

The ratings and counts and how they were obtained will be described in the following paragraphs. For ratings obtained by ourselves, a different group of participants provided the data for each variable (ratings for all variables are given in Appendix B). The participants providing rating data did not participate in either naming task. For all the continuous measures, an increase in value represents an increase in the size of the variable under study (e.g., for decomposability, the larger the value, the greater the decomposition). Mean values and standard deviations for each variable for animals, fruit and vegetables, and all living and nonliving things are given in Table 1.

Complexity (e.g., Carrasco \& Seamon, 1996; Cutzu \& Tarr, 1999; Ellis \& Morrison, 1998; Gerlach, 2001; Long \& Wurst, 1984; Snod- grass \& Vanderwart, 1980). Ratings were obtained from Snodgrass and Vanderwart, who judged how complex the picture of an object was in terms of its details or intricacy. Raters were instructed to rate the picture itself, rather than the object it represented.

Decomposability (Biederman, 1987; Lloyd-Jones \& Luckhurst, 2002a). Booklets were completed by 34 participants, who were undergraduates at the University of Kent, and received program credits for participation. There were approximately 20 pictures per page. All the pictures were presented in a random order in which each participant received a different random order of the pages of the booklet, and the pictures were randomly ordered within each page of the booklet for each participant. The participants were instructed to decide into how many visual parts each picture could be decomposed. They were also told that parts need not be nameable but that they must be visible in the drawings. We calculated the average decomposability for each picture across the 34 raters.

Contour overlap (e.g., Humphreys et al., 1988; Lloyd-Jones \& Humphreys, 1997a, 1997b; Tranel et al., 1997). Measures of percentage of contour overlap for each category were obtained from G. W. Humphreys (personal communication; cited in Humphreys et al., 1988). This measure involved taking the Snodgrass and Vanderwart (1980) pictures, normalizing them into a prototypical orientation and size, excluding internal detail, and overlaying a grid on each item with every other item in turn, in order to calculate the percentage of overlap of contour between a particular object and other members of its category (where category was defined according to Snodgrass \& Vanderwart, 1980; see above for a list of categories). The measure is, therefore, abstracted, to some degree, from the original picture.

Imageability (e.g., Ellis \& Morrison, 1998; Marcel \& Patterson, 1978; Morrison et al., 1992; Nickels, 1995; Nickels \& Howard, 1994; Plaut \& Shallice, 1993; Strain et al., 1995). Twenty-seven participants completed booklets, with approximately 40 picture names per page. All the names were presented in a random order; each participant received a different random order of the pages of the booklet, and the names were randomly ordered within each page of the booklet for each participant. Instructions were to rate the ease or difficulty with which the words aroused mental images, on a scale of 1-7 (closely following the instructions of Gilhooly \& Logie, 1980, whereby the higher the score, the more easily an image is aroused). Average ratings of imageability were calculated for each picture across the 27 raters.

Age of acquisition (e.g., Barry et al., 1997; Ellis \& Morrison, 1998; Snodgrass \& Yuditsky, 1996). Ratings were obtained from Snodgrass and Yuditsky, ${ }^{2}$ who used the same instructions and scale as Carroll and White (1973). The participants rated their best estimate of when, in their life, they had first learned the word and its meaning, in either spoken or written form.

Name frequency (e.g., Barry et al., 1997; Snodgrass \& Yuditsky, 1996). The measure of spoken word frequency was taken from the CELEX spoken frequency database, which sampled 1,300,000 spoken words. Log name frequency will be used throughout.

Table 2 presents the significant zero-order correlations among the independent variables. Overall, the pattern of intercorrelations between variables is in line with previous studies (e.g., Barry et al.,

Table 1

Means and Standard Deviations for Animals, Fruit and Vegetables (F/V), All Living Things, and Nonliving Things for Each of the Independent Variables

\begin{tabular}{|c|c|c|c|c|c|c|c|c|}
\hline \multirow[b]{2}{*}{ Variable } & \multicolumn{2}{|c|}{ Animals } & \multicolumn{2}{|c|}{ F/V } & \multicolumn{2}{|c|}{ All Living } & \multicolumn{2}{|c|}{ Nonliving } \\
\hline & $M$ & $S D$ & $M$ & $S D$ & $M$ & $S D$ & $M$ & $S D$ \\
\hline Complexity & 3.86 & 0.49 & 2.70 & 0.86 & 3.46 & 0.84 & 2.72 & 0.75 \\
\hline Decomposability & 9.10 & 1.69 & 3.91 & 3.23 & 7.34 & 3.37 & 5.60 & 3.41 \\
\hline Contour overlap & 15.93 & 4.60 & 18.58 & 6.65 & 16.82 & 5.48 & 12.05 & 4.89 \\
\hline Imageability & 5.94 & 0.65 & 5.86 & 0.70 & 5.92 & 0.67 & 5.78 & 0.77 \\
\hline Age of acquisition & 3.98 & 0.77 & 3.99 & 0.90 & 3.98 & 0.82 & 3.95 & 0.91 \\
\hline Name frequency $(\log )$ & 0.71 & 0.52 & 0.66 & 0.41 & 0.69 & 0.48 & 1.06 & 0.73 \\
\hline
\end{tabular}


1997; Snodgrass \& Vanderwart, 1980; Snodgrass \& Yuditsky, 1996). Complexity and decomposability are highly positively intercorrelated. Age of acquisition correlates highly with name frequency (e.g., Barry et al., 1997; Snodgrass \& Yuditsky, 1996). However, age of acquisition also correlates with imageability, which might suggest both a semantic and a lexical (phonological) locus for the effects of the former variable. Contour overlap does not correlate highly with complexity or decomposability. This is consistent with visual similarity and complexity's tapping different visual processes in object recognition. Recent studies have shown that both outline contour information (e.g., the contour of a 2-D object depiction in silhouette) and non-outline-contour information (e.g., internal details of a 2-D object depiction) can contribute independently to object recognition (e.g., Hayward, Tarr, \& Corderoy, 1999; Lloyd-Jones \& Luckhurst, 2002a). Finally, as was expected, living things had greater contour overlap and were also more complex, more decomposable, and of lower name frequency.

\section{Design and Procedure}

Each task (naming without deadline and naming with deadline) was carried out by an independent group of participants. The deadline procedure was the same as that in Vitkovitch et al. (1993). For both tasks, the 204 stimuli were presented in two blocks of equal size and in random order within each block, for each participant. Order of block presentation was counterbalanced across participants. A short break was given between blocks. Each participant received six practice trials, using stimuli otherwise not presented in the experiment. The stimuli were left on screen until response, and the intertrial interval was approximately $5 \mathrm{sec}$. For naming without deadline, the participants were asked to respond as quickly as possible while maintaining accuracy. For naming with deadline, the procedure was the same as that for naming without deadline, except that $600 \mathrm{msec}$ after the onset of each picture an auditory beep accompanied the disappearance of the picture. The participants were instructed to try to respond to "beat the beep" and to report the first name they thought of on seeing the object. Following Vitkovitch and Humphreys (1991, p. 668), the delay of $600 \mathrm{msec}$ was chosen as a result of inspection of individual RTs to a wide range of picture stimuli used in previous naming experiments reported by Humphreys et al. (1988). Few RTs were shorter than $600 \mathrm{msec}$, and therefore, this deadline was expected to put considerable external pressure on most (naive) participants.

\section{RESULTS}

To summarize our main findings, we first will report across-task analyses, which showed that the deadline influenced performance, increasing the proportion of errors, relative to the naming-without-deadline task. ${ }^{3}$ In particular, the deadline increased the proportion of visual-semantic, pure semantic, and pure visual errors. The analyses also showed living versus nonliving category differences in performance, with the deadline increasing the proportion of overall errors and of visual-semantic errors more for living things and increasing the proportion of pure semantic errors more for nonliving things. Importantly, there was also evidence for more visual-semantic errors to animals than to fruit and vegetables.

Using multiple regression, we examined the influence of complexity, decomposability, contour overlap, imageability, age of acquisition, and name frequency on RTs in naming without deadline ${ }^{4}$ and on the main types of error produced under deadline conditions (note that there were too few errors in the naming-without-deadline task for analysis). We calculated each error rate taking accuracy into account (i.e., error/error + correct responses). The main findings were that (1) complexity and contour overlap were associated with the production of visual-semantic errors, whereas imageability and age of acquisition were associated with the production of pure semantic errors, and (2) complexity was associated with visual-semantic errors to animals, whereas contour overlap was associated with visual-semantic errors to fruit and vegetables.

\section{Across-Task Analyses}

The factors in the following ANOVAs were task (naming without deadline vs. naming with deadline) and category (either living vs. nonliving things or animals vs. fruit and vegetables vs. nonliving things). The dependent variables were overall accuracy and proportion of visual-semantic, pure semantic, and pure visual errors. Because there were unequal numbers of living and nonliving things (71 and 133 items, respectively), we were concerned that parametric analysis might not be robust. However, the ratio of the largest to the smallest sample size was considerably less than $4: 1$, and the ratio between the largest and the smallest variance (i.e., standard deviation squared) was considerably less than 10:1. For the comparison between animals (47 items), fruit and vegetables (24 items), and nonliving things (133 items), the second of the conditions above applied - namely, that the ratio between the smallest and the largest variances was considerably below 10:1. Parametric analysis was, therefore, considered robust to violation of the assumption of homogeneity of variance (Tabachnick \& Fidell, 1996, p. 328). In addition, analyses using nonparametric tests were highly significant in all cases, and so we will report only the results of the parametric tests that present a clearer and more efficient analysis of the data.

Error classification was determined using a procedure similar to that in Vitkovitch et al. (1993, pp. 246-247). Naming responses were considered correct if they corre-

Table 2

Zero Order Correlations Among the Independent Variables (for All 204 Items)

\begin{tabular}{lcccccc}
\hline \multicolumn{1}{c}{ Variable } & $\mathrm{C}$ & $\mathrm{D}$ & $\mathrm{CO}$ & $\mathrm{I}$ & $\mathrm{AA}$ & $\mathrm{NF}$ \\
\hline Complexity (C) & & & & & & \\
Decomposability (D) & $+.67^{* *}$ & & & & & \\
Contour overlap (CO) & +.02 & -.10 & & & & \\
Imageability (I) & +.01 & +.09 & -.05 & & & \\
Age of acquisition (AA) & $+.15^{*}$ & -.08 & +.11 & $-.38^{* *}$ & & \\
Name frequency (log) (NF) & -.10 & +.10 & -.10 & $+.26^{* *}$ & $-.51^{* *}$ & \\
Living/nonliving & $-.41^{* *}$ & $-.24^{* *}$ & $-.41^{* *}$ & -.09 & -.02 & $+.26^{* *}$ \\
\hline Note-Critical value of $r=.138, p<.05$ (two-tailed test). & ${ }^{*} p<.05$. & ${ }^{* *} p<.01$. &
\end{tabular}


sponded to the names given in the Snodgrass and Vanderwart (1980) set. However, participants given unlimited time may disagree on the appropriate name, and some objects may be referred to by alternative names that may be considered correct. We therefore took the criterion that a minimum of $10 \%$ of the participants tested by Snodgrass and Vanderwart (4/40 participants) had to have given the same response for a name to be accepted as a correct alternative to the dominant name. For instance, most participants referred to the object chicken by the name chicken, but more than $10 \%$ considered hen appropriate. This was, therefore, not considered an error. We also accepted names as correct if an alternative name was given by at least $25 \%$ of our participants within each task (in this way, for instance, tortoise became the dominant name for turtle). Following this procedure, 13 alternative names for 12 objects were accepted as correct $(12 / 204=6.37 \%$ of the objects were affected). The remaining responses were designated errors, although objects referred to by superordinate terms (e.g., leek named as vegetable) were considered separately. Superordinate naming does not reflect accurate naming, but neither is it strictly an error. Moreover, a preliminary survey of the data revealed that a few participants used the superordinate term several times, possibly as a strategy for beating the deadline. In line with Vitkovitch et al. (1993; Vitkovitch \& Humphreys, 1991), therefore, we will report but will not analyze superordinate errors.

Five independent judges were asked to classify the naming errors according to whether they could be considered to reflect only visual similarity to the intended target (pure visual), semantic similarity (pure semantic), or both visual and semantic similarity (visual-semantic). In addition, errors were classified according to whether they were considered to refer to a superordinate term (e.g., an orange named as fruit; superordinate), reflect semantic and phonological similarity to the target, or reflect only phonological similarity to the target (no such errors were observed). Finally, whereas Vitkovitch et al. (1993) had one category of unrelated errors, for increased precision and because we had a greater number of categories, we subdivided this category into across-category errors (those errors not within the same basic category but within the broader superordinate category of living or nonliving things; e.g., a fruit named as vegetable) and unrelated errors (those errors that were in the opposite category of living or nonliving things, don't know responses, and completely random/bizarre responses). An item could be classified only under one error type. In the analysis of category, error proportions were calculated as a function of living/nonliving or animal/ fruit-and-vegetable category size.

For both independent and dependent multiple regression variable values, we used the dominant response (e.g., chicken, rather than hen). However, there were cases in which the dominant name was not as representative of the object as we might wish (e.g., for a blouse, 13 responses were blouse, 10 shirt, 6 jacket, and 1 coat). We therefore repeated the regression analyses, dropping items with less than $65 \%$ name agreement (the percentage of name agreement for each item is given in Appendix B). The same variables showed a significant association, and no new associations were evident [while noting that for namingwithout-deadline RTs, the living/nonliving variable became marginally nonsignificant $\left(R^{2}=.36, \beta=-0.15\right.$; squared $t$ ratio $=4.04, p=.05)]$. We also repeated the regression analyses, either (1) replacing the value of a variable for which no rating was available with the mean of the values for other members of the same category (i.e., living vs. nonliving things or animals vs. fruit and vegetables; cf. Tabachnick \& Fidell, 1996) or (2) dropping the item. Only a small number of items were dealt with in this way, and in all cases, the results were unaltered.

For animals, fruit and vegetables, and all living and nonliving things, Table 3 presents the proportion of errors in naming with and without deadline (i.e., the proportion of each type of error over the total number of trials), the relative percentages of each error type (i.e., the percentage of each type of error over the total number of errors; see note 3 ), percentage correct, and naming latencies for naming without deadline (we were unable to collect naming-with-deadline latencies, due to a limitation in the software).

Subscripts 1 and 2 will refer to by-subjects analyses (across items in a particular condition) and by-item analyses (across subjects in a particular condition), respectively. Main effects or interactions that failed to reach significance will not be reported. Planned comparisons used the cell means tests advocated by Toothaker (1993, pp. 74-78). Alpha was set at $p<.05$.

\section{Living/Nonliving Things}

Overall errors. There was a main effect of task, with more errors in the naming-with-deadline task $\left[F_{1}(1,58)=\right.$ $60.9, M S_{\mathrm{e}}=18.2, p<.0005 ; F_{2}(1,202)=73.3, M S_{\mathrm{e}}=$ $0.97, p<.0005]$. There was also a main effect of category, with more errors to living things $\left[F_{1}(1,58)=186.2\right.$, $M S_{\mathrm{e}}=9.4, p<.0005 ; F_{2}(1,202)=39.6, M S_{\mathrm{e}}=2.8, p<$ $.0005]$. Furthermore, there was a task $\times$ category interaction $\left[F_{1}(1,58)=20.7, M S_{\mathrm{e}}=9.4, p<.0005 ; F_{2}(1,202)=\right.$ 13.4, $\left.M S_{\mathrm{e}}=0.97, p<.0005\right]$. Planned comparisons confirmed a difference between naming with and without deadline for both living (16.3 vs. 7.78, respectively; $p<$ .0005 ) and nonliving (5.96 vs. 2.45 , respectively; $p<$ .0005) things. The difference between naming with and without deadline was greater for living than for nonliving things.

Visual-semantic errors. There was a main effect of task, with more visual-semantic errors in the naming-withdeadline task $\left[F_{1}(1,58)=46.1, M S_{\mathrm{e}}=6.9, p<.0005\right.$; $\left.F_{2}(1,202)=34.8, M S_{\mathrm{e}}=25, p<.0005\right]$. There was also a main effect of category, with more visual-semantic errors to living things $\left[F_{1}(1,58)=279.6, M S_{\mathrm{e}}=6, p<.0005\right.$; $\left.F_{2}(1,202)=67.5, M S_{\mathrm{e}}=75.3, p<.0005\right]$. Furthermore, there was a task $\times$ category interaction $\left[F_{1}(1,58)=30.9\right.$, $M S_{\mathrm{e}}=6, p<.0005 ; F_{2}(1,202)=23.4, M S_{\mathrm{e}}=25, p<$ $.0005]$. Planned comparisons confirmed a difference between naming with and without deadline for both living (11.45 vs. 5.68, respectively; $p<.0005$ ) and nonliving ( 1.45 vs. 0.67 , respectively; $p<.0005$ ) things. The difference between naming with and without deadline was greater for living than for nonliving things. 
Table 3

Percentages of Animals, Fruit and Vegetables (F/V), All Living, and Nonliving Naming Errors (\%E), Relative Percentages of Each Error Type (\%RE), Percentages Correct, and Naming Latencies (in Milliseconds, With Standard Deviations for Without-Deadline Condition Only)

\begin{tabular}{|c|c|c|c|c|c|c|c|c|c|c|c|c|c|c|c|c|}
\hline \multirow[b]{3}{*}{ Error Type } & \multicolumn{8}{|c|}{ Naming Without Deadline } & \multicolumn{8}{|c|}{ Naming With Deadline } \\
\hline & \multicolumn{2}{|c|}{ Animals } & \multicolumn{2}{|c|}{$\mathrm{F} / \mathrm{V}$} & \multicolumn{2}{|c|}{ All Living } & \multicolumn{2}{|c|}{ Nonliving } & \multicolumn{2}{|c|}{ Animals } & \multicolumn{2}{|c|}{$\mathrm{F} / \mathrm{V}$} & \multicolumn{2}{|c|}{ All Living } & \multicolumn{2}{|c|}{ Nonliving } \\
\hline & $\% \mathrm{E}$ & $\% \mathrm{RE}$ & $\% \mathrm{E}$ & $\% \mathrm{RE}$ & $\% \mathrm{E}$ & $\% \mathrm{RE}$ & $\% \mathrm{E}$ & $\% \mathrm{RE}$ & $\% \mathrm{E}$ & $\% \mathrm{RE}$ & $\% \mathrm{E}$ & $\% \mathrm{RE}$ & $\% \mathrm{E}$ & $\% \mathrm{RE}$ & $\% \mathrm{E}$ & $\% \mathrm{RE}$ \\
\hline Visual-semantic & 5.89 & 74.18 & 5.28 & 70.40 & 5.68 & 73.01 & 0.67 & 27.35 & 12.27 & 75.55 & 9.86 & 59.65 & 11.45 & 70.25 & 1.45 & 24.33 \\
\hline Pure semantic & 0.00 & 0.00 & 0.00 & 0.00 & 0.00 & 0.00 & 0.75 & 30.61 & 0.35 & 2.15 & 0.00 & 0.00 & 0.23 & 1.41 & 2.80 & 46.98 \\
\hline Pure visual & 0.07 & 0.88 & 0.14 & 1.87 & 0.09 & 1.16 & 0.52 & 21.22 & 0.07 & 0.43 & 1.25 & 7.56 & 0.46 & 2.82 & 1.30 & 21.81 \\
\hline Superordinate & 1.42 & 17.88 & 0.00 & 0.00 & 0.94 & 12.08 & 0.07 & 2.86 & 2.91 & 17.91 & 0.97 & 5.86 & 2.25 & 13.80 & 0.02 & 0.34 \\
\hline Semantic-phonological & 0.21 & 2.64 & 0.00 & 0.00 & 0.14 & 1.80 & 0.02 & 0.82 & 0.43 & 2.65 & 0.42 & 2.54 & 0.42 & 2.58 & 0.27 & 4.53 \\
\hline Across category & 0.00 & 0.00 & 0.14 & 1.86 & 0.04 & 0.51 & 0.00 & 0.00 & 0.07 & 0.43 & 3.75 & 22.69 & 1.31 & 8.04 & 0.00 & 0.00 \\
\hline Unrelated & 0.35 & 4.40 & 1.94 & 25.86 & 0.89 & 11.44 & 0.42 & 17.14 & 0.14 & 0.86 & 0.28 & 1.69 & 0.18 & 1.10 & 0.12 & 2.01 \\
\hline Percentage correct & \multicolumn{2}{|c|}{92.06} & \multicolumn{2}{|c|}{92.50} & \multicolumn{2}{|c|}{92.22} & \multicolumn{2}{|c|}{97.55} & \multicolumn{2}{|l|}{83.76} & \multicolumn{2}{|l|}{83.47} & \multicolumn{2}{|l|}{83.70} & \multicolumn{2}{|l|}{94.04} \\
\hline Naming latency $(S D)$ & \multicolumn{2}{|c|}{$1,048(147)$} & \multicolumn{2}{|c|}{$1,126(225)$} & \multicolumn{2}{|c|}{$1,073(145)$} & \multicolumn{2}{|c|}{$956(105)$} & \multicolumn{2}{|l|}{-} & \multicolumn{2}{|l|}{-} & \multicolumn{2}{|l|}{-} & \multicolumn{2}{|l|}{-} \\
\hline
\end{tabular}

Pure semantic errors. There was a main effect of task, with more pure semantic errors in the naming-withdeadline task $\left[F_{1}(1,58)=55.3, M S_{\mathrm{e}}=0.71, p<.0005\right.$; $\left.F_{2}(1,202)=14.8, M S_{\mathrm{e}}=10.3, p<.0005\right]$. There was also a main effect of category, with more pure semantic errors to nonliving things $\left[F_{1}(1,58)=131.9, M S_{\mathrm{e}}=0.62\right.$, $\left.p<.0005 ; F_{2}(1,202)=13.1, M S_{\mathrm{e}}=16.3, p<.0005\right]$. Furthermore, there was a task $\times$ category interaction $\left[F_{1}(1,58)=39.6, M S_{\mathrm{e}}=0.62, p<.0005 ; F_{2}(1,202)=\right.$ $\left.10.7, M S_{\mathrm{e}}=10.3, p<.0005\right]$. Planned comparisons confirmed a difference between naming with and without deadline for nonliving things ( 2.80 vs. 0.75 , respectively; $p<.0005)$ and a marginally nonsignificant difference for living things ( 0.23 vs. 0 , respectively; $p=.05$ ). The difference between naming with and without deadline was greater for nonliving than for living things.

Pure visual errors. There was a main effect of task, with more pure visual errors in the naming-with-deadline task $\left[F_{1}(1,58)=17.13, M S_{\mathrm{e}}=0.05, p<.0005 ; F_{2}(1,202)=\right.$ $\left.4.45, M S_{\mathrm{e}}=6.82, p<.05\right]$. There was also a main effect of category, by subjects only, with more pure visual errors to nonliving things $\left[F_{1}(1,58)=25.8, M S_{\mathrm{e}}=0.46, p<.0005\right.$; $F_{2}(1,202)=3.36, M S_{\mathrm{e}}=11.02, p=$ n.s.]. However, there was no task $\times$ category interaction $\left(F_{1}<2.61, F_{2}<1\right)$.

\section{Animals/Fruit and Vegetables/Nonliving Things}

Overall errors. There was a main effect of task, with more errors in the naming-with-deadline task $\left[F_{1}(1,58)=\right.$ $55.1, M S_{\mathrm{e}}=39.3, p<.0005 ; F_{2}(1,201)=66.9, M S_{\mathrm{e}}=$ $0.98, p<.0005]$. There was also a main effect of category $\left[F_{1}(2,116)=51.7, M S_{\mathrm{e}}=23.6, p<.0005 ; F_{2}(2,201)=\right.$ $\left.19.7, M S_{\mathrm{e}}=2.8, p<.0005\right]$. Planned comparisons confirmed more errors for the animals than for nonliving things (12.09 vs. 4.20 , respectively; $p<.0005)$ and for fruit and vegetables than for nonliving things (12.01 vs. 4.20 , respectively; $p<.0005$ ). There was no difference between the animal and the fruit and vegetable categories.

In addition, there was a task $\times$ category interaction $\left[F_{1}(2,116)=5.7, M S_{\mathrm{e}}=23.6, p<.005 ; F_{2}(2,201)=6.7\right.$, $\left.M S_{\mathrm{e}}=0.98, p<.001\right]$. Planned comparisons confirmed a difference between naming-with and -without deadline for animals (16.24 vs. 7.94, respectively; $p<.0005$ ), fruit and vegetables (16.53 vs. 7.50 , respectively; $p<.0005)$, and nonliving things (5.96 vs. 2.45 , respectively; $p<.0005$ ). The interaction can be attributed to the fact that the difference between naming with and without deadline was greater for animals than for nonliving things ( 8.30 vs. 3.51, respectively) and for fruit and vegetables than for nonliving things (9.03 vs. 3.51, respectively), whereas there was little difference between animals and fruit and vegetables.

Visual-semantic errors. There was a main effect of task, with more errors in the naming-with-deadline task $\left[F_{1}(1,58)=38.3, M S_{\mathrm{e}}=18.1, p<.0005 ; F_{2}(1,201)=\right.$ 35.3, $\left.M S_{\mathrm{e}}=25.1, p<.0005\right]$. There was also a main effect of category $\left[F_{1}(2,116)=88.8, M S_{\mathrm{e}}=12.3, p<\right.$ $\left..0005 ; F_{2}(2,201)=34.6, M S_{\mathrm{e}}=75.1, p<.0005\right]$. Planned comparisons confirmed more visual-semantic errors for animals than for nonliving things ( 9.08 vs. 1.06 , respectively; $p<.0005)$ and for fruit and vegetables than for nonliving things ( 7.57 vs. 1.06 , respectively; $p<.0005$ ). Importantly, there were also more visual-semantic errors for animals than for fruit and vegetables $(p<.05)$.

Furthermore, there was a task $\times$ category interaction $\left[F_{1}(2,116)=10.1, M S_{\mathrm{e}}=12.3, p<.0005 ; F_{2}(2,201)=\right.$ $\left.12.2, M S_{\mathrm{e}}=25.1, p<.0005\right]$. Planned comparisons confirmed a difference between naming with and without deadline for animals (12.27 vs. 5.89, respectively; $p<$ $.0005)$, fruit and vegetables (9.86 vs. 5.28, respectively; $p<.001$ ), and nonliving things (1.45 vs. 0.67, respectively; $p<.0005$ ). To examine whether the interaction arose because the difference between naming with and without deadline for each category could be rank ordered, with a greater difference for animals (6.38) versus fruit and vegetables (4.58) versus nonliving things $(0.78)$, we conducted separate ANOVAs for each pair of categories. As was expected, comparisons both of animals and of fruit and vegetables with nonliving things produced highly significant main effects and interactions in all cases [e.g., for animals vs. nonliving things, the task $\times$ category interaction was $F_{1}(1,58)=30.1, p<.0005$, and $F_{2}(1,178)=$ $22.2, p<.0005$; for fruit and vegetables vs. nonliving things, the task $\times$ category interaction was $F_{1}(1,58)=$ $8.3, p<.005$, and $\left.F_{2}(1,155)=14.2, p<.0005\right]$. Thus, the deadline increased visual-semantic errors more both for animals and for fruit and vegetables than for nonliving things. For the main comparison of interest, however- 
namely, animals versus fruit and vegetables - there was no interaction between task and category $\left(F_{1}<1.6, F_{2}<1\right)$. Therefore, although there were more errors overall for animals, the deadline did not produce a greater increase in such errors for animals than for fruit and vegetables.

Pure semantic errors. There was a main effect of task, with more errors in the naming-with-deadline task $\left[F_{1}(1,58)=50.2, M S_{\mathrm{e}}=0.58, p<.0005 ; F_{2}(1,201)=\right.$ 4.8, $\left.M S_{\mathrm{e}}=10.4, p<.05\right]$. There was also a main effect of category $\left[F_{1}(2,116)=111.8, M S_{\mathrm{e}}=0.51, p<.0005\right.$; $\left.F_{2}(2,201)=6.5, M S_{\mathrm{e}}=16.4, p<.005\right]$. Planned comparisons confirmed more pure semantic errors for nonliving things than for animals ( 1.77 vs. 0.17 , respectively; $p<.0005)$ and for nonliving things than for fruit and vegetables ( 1.77 vs. 0 , respectively; $p<.0005$ ). There was no difference between animals and fruit and vegetables.

In addition, there was a task $\times$ category interaction $\left[F_{1}(2,116)=35.2, M S_{\mathrm{e}}=0.51, p<.0005 ; F_{2}(2,201)=\right.$ 5.4, $\left.M S_{\mathrm{e}}=10.4, p<.005\right]$. Planned comparisons confirmed a difference between naming with and without deadline only for nonliving things $(2.80 \mathrm{vs}$. 0.75 , respectively; $p<.0005$ ).

Pure visual errors. There was a main effect of task, with more errors in the naming-with-deadline task $\left[F_{1}(1,58)=12.6, M S_{\mathrm{e}}=1.4, p<.001 ; F_{2}(1,201)=4.2\right.$, $\left.M S_{\mathrm{e}}=6.8, p<.05\right]$. There was also a main effect of category by subjects only $\left[F_{1}(2,116)=11.2, M S_{\mathrm{e}}=1.1, p<\right.$ $.0005 ; F_{2}(2,201)=2.4, M S_{\mathrm{e}}=10.9, p=$ n.s.]. Planned comparisons confirmed more pure visual errors for nonliving things than for animals (.91 vs. .07, respectively; $p<.0005)$ and for fruit and vegetables than for animals (.69 vs. .07, respectively; $p<.005$ ). There was no difference between nonliving things and fruit and vegetables.

In addition, there was a task $\times$ category interaction by subjects only $\left[F_{1}(2,116)=4.7, M S_{\mathrm{e}}=1.03, p<.05\right.$; $F_{2}(2,201)=0.88, M S_{\mathrm{e}}=6.8, p=$ n.s.]. Planned comparisons confirmed a difference between naming with and without deadline only for nonliving things ( $1.30 \mathrm{vs} .0 .52$, respectively; $p<.0005$ ) and fruit and vegetables (1.25 vs. 0.14 , respectively; $p<.05)$. A separate ANOVA directly comparing nonliving things and animals did not find a task $\times$ category interaction $\left(F_{\mathrm{S}}<1\right)$, and therefore, the deadline produced a similar increase in pure visual errors for nonliving things and for fruit and vegetables.

\section{Multiple Regression Analyses}

In the following simultaneous multiple regression analysis, we determined which variables influenced RTs in naming without deadline and the major kinds of error produced under deadline conditions. We should note the possible concern of multicollinearity (e.g., Tabachnick \& Fidell, 1996). When the independent variables are highly correlated, power is compromised because the estimates of the regression coefficients and their standard errors can fluctuate a great deal. Moreover, because of their high correlation, the effects of the independent variables are confounded. In the present case, there was a reasonably high correlation between visual complexity and decomposability $(r=.67)$. We therefore repeated each analysis, including one and not the other variable (cf. Gilhooly, 1984; Mor- rison, 2003; Nickels \& Howard, 1994). In all cases, the findings were unchanged. We did the same for age of acquisition and name frequency $(r=.51)$. In this case, name frequency became a predictor when age of acquisition was omitted (whereby name frequency was associated with the same dependent variables as age of acquisition). ${ }^{5}$ We note also that in all cases, tolerance (i.e., the proportion of the variance for the variable in question that is not due to other variables) was greater than .446 (ranging from .447 to .999 , where a value close to 1 means that you are very safe and a value close to 0 means that there is a danger of multicollinearity). Finally, when regression is carried out on items (rather than on participants), there is a problem of independence of errors of prediction, and we need to be concerned about the independence of the residual scores. However, this was not an issue here, since the Durbin-Watson statistic was approximately 2 (ranging from 1.79-2.06, where the more this value deviates from 2 , the more likely it is that the residuals are not independent).

Table 4 presents the correlation of each variable with the RTs in naming without deadline, and percentage correct, visual-semantic errors, pure semantic errors, and pure visual errors for naming with deadline. Table 5 presents statistical summaries of the multiple regression analyses examining the influence of individual variables on RTs in naming without deadline, percentages correct and percentages of visual-semantic, pure semantic, and pure visual errors for naming with deadline. We also determine the "usefulness" of predictors, using the square of the $t$ ratio (which is equivalent to the squared semipartial correlation statistic; see, e.g., Howell, 1997). The main finding was that complexity and contour overlap were associated with the production of visual-semantic errors and imageability and age of acquisition were associated with the production of pure semantic errors. There were also a relatively small number of pure visual errors, which were associated with age of acquisition. They occurred primarily to objects with a single strongly associated item that may be considered a competitor (e.g., toaster-box), rather than with a cluster of competitors, as was the case for visual-semantic errors (e.g., celery-asparagus, $c u$ cumber, broccoli, carrot), and given their small proportion, we will not discuss them further.

Simultaneous multiple regression analyses conducted separately on living and nonliving things generally showed the same pattern of variable influences as above, when one takes into account the fact that there were more visual-semantic errors to living things and more pure semantic errors to nonliving things, as was described earlier (and therefore, the summary statistics for the regression analyses on living and nonliving categories are presented in Appendix C). However, regression analyses conducted separately on animals versus fruit and vegetables showed evidence of contrasting findings. Of most interest, complexity was associated with RTs in naming without deadline and with percentages correct and percentages of visual-semantic errors to animals under deadline conditions. In contrast, contour overlap (but not complexity) was associated with percentages correct and percentages of visual-semantic errors to fruit and vegetables under 
Table 4

Correlations of the Individual Variables With Naming-WithoutDeadline Response Times (RTs) and With Percentages Correct (\%) and Percentages of Visual-Semantic (VS), Pure Semantic, and Pure Visual Errors Under Deadline Conditions

\begin{tabular}{llclll}
\hline & & & \multicolumn{3}{c}{ Error Type } \\
\cline { 5 - 6 } \multicolumn{1}{c}{ Variable } & $\mathrm{RT}$ & $\%$ & $\mathrm{VS}$ & Semantic & Visual \\
\hline Complexity & $+.26^{* *}$ & $-.27^{* *}$ & $+.34^{* *}$ & $-.16^{*}$ & +.02 \\
Decomposability & +.03 & -.05 & $+.15^{*}$ & -.09 & -.10 \\
Contour overlap & $+.28^{* *}$ & $-.35^{* *}$ & $+.33^{* *}$ & -.08 & +.06 \\
Imageability & $-.37^{* *}$ & +.11 & -.06 & +.04 & -.12 \\
Age of acquisition & $+.41^{* *}$ & $-.30^{* *}$ & +.13 & +.13 & $+.25^{* *}$ \\
Name frequency (log) & $-.35^{* *}$ & $+.27^{* *}$ & $-.20^{* *}$ & -.06 & -.10 \\
Living/nonliving & $-.26^{* *}$ & $+.39^{* *}$ & $-.54^{* *}$ & $+.26^{* *}$ & +.09 \\
\hline Note-Critical value of $r=.138, p<.05($ two-tailed test). & ${ }^{*} p<$ \\
$.05 . \quad{ }^{* *} p<.01$. & & & & &
\end{tabular}

deadline conditions (although the overall regression was not significant).

Table 6 presents statistical summaries of the multiple regression analyses examining the association of individual variables with RTs in naming without deadline and with percentages correct and percentages of visual-semantic errors for animals versus fruit and vegetables (there were no findings for pure semantic and pure visual errors, and they will not be reported).

\section{DISCUSSION}

The main findings were as follows. (1) The imposition of a deadline clearly exaggerated errors found in naming without deadline, and it did so across a large range of items. This increase in error was generally of the same magnitude for the main error types (although there was some evidence for a disproportionate increase in pure semantic errors; see note 3). (2) The majority of errors were visually and semantically related to the target. There were more of these errors for living than for nonliving things overall, and the deadline also produced a greater increase in their number for living than for nonliving things. There was also a small number of pure semantic errors. There were more of these errors for nonliving than for living things overall, and the deadline also produced a greater increase in their number for nonliving than for living things. (3) Overall, there were more visual-semantic errors for animals than for fruit and vegetables. (4) The main variables associated with RTs under naming without deadline were also the variables that were associated with the production of errors under deadline conditions. These variables were visual complexity, contour overlap, imageability, and age of acquisition. (5) For animals, visualsemantic errors in naming with deadline and, also, RTs in naming without deadline were associated with visual complexity, whereas for fruit and vegetables they were associated with visual similarity. (6) Finally, we note that overall, visual-semantic errors were associated with visual complexity and visual similarity, whereas pure semantic errors were associated with imageability and age of acquisition. Let us now interpret these findings in terms of theories encompassing category-specific deficits in the neuropsychological literature.

We will begin by focusing on visual-semantic errors. The evidence for more visual-semantic errors for living things than nonliving things is consistent with SF theory, whereby sensory features are important for describing living things and functional features are important for describing nonliving things (Farah \& McClelland, 1991; Warrington \& Shallice, 1984). However, we also found more visual-semantic errors to animals than to fruit and vegetables, which is not consistent with this account. Nevertheless, there are two points to make here. First, on the basis of SF theory, a number of theorists have proposed that a difficulty in processing visual knowledge should accompany a difficulty with living things (e.g., Caramazza \& Shelton, 1998). The data have not always supported this argument (e.g., Caramazza \& Shelton, 1998; Lambon Ralph, Howard, Nightingale, \& Ellis, 1998). Nevertheless, as we shall see, findings from the present experiment are consistent with this proposal. Second and more important, although SF theory cannot account for all the present data, a development of the knowledge type approach by Cree and McRae (2003) may be able to account for our findings. We now will briefly address this question.

Category differences in the present experiment may have been due solely to initial baseline differences be-

Table 5

Values of $R \mathrm{~s}$, Beta Coefficients, and Squared $\boldsymbol{t}$ Ratios (for Significant Predictors, in Parentheses) for All Items and for Variables Associated With Naming-Without-Deadline Response Times (RTs) and With Percentages Correct (\%) and Percentages of Visual-Semantic, Pure Semantic, and Pure Visual Errors in Naming With Deadline

\begin{tabular}{|c|c|c|c|c|c|}
\hline \multirow[b]{2}{*}{ Variable } & \multirow[b]{2}{*}{ RT } & \multirow[b]{2}{*}{$\%$} & \multicolumn{3}{|c|}{ Error Type } \\
\hline & & & Visual-Semantic & Semantic & Visual \\
\hline Complexity & $+.22 *(6.77)$ & $-.18^{*}(3.88)$ & $+.20^{*}(5.14)$ & -.14 & +.12 \\
\hline Decomposability & -.08 & +.07 & -.05 & +.08 & -.13 \\
\hline Contour overlap & $+.17^{* *}(6.97)$ & $-.22^{* *}(9.98)$ & $+.14^{*}(4.44)$ & +.02 & +.09 \\
\hline Imageability & $-.27^{* * *}(18.06)$ & +.02 & -.08 & $+.15^{*}(4.24)$ & -.01 \\
\hline Age of acquisition & $+.19^{*}(6.76)$ & $-.21^{* *}(7.95)$ & +.05 & $+.18^{*}(4.14)$ & $+.24^{* *}(7.51)$ \\
\hline Name frequency $(\log )$ & -.10 & +.04 & -.01 & -.10 & +.01 \\
\hline Living/nonliving & -.11 & $+.24^{* *}(9.24)$ & $-.36^{* * *}(21.77)$ & $+.26^{* *}(9.17)$ & +.13 \\
\hline Multiple $R^{2}$ & .35 & .29 & .30 & .12 & .10 \\
\hline$F$ value & 14.97 & 11.63 & 12.12 & 3.70 & 3.02 \\
\hline Significance $(p)$ & $<.0005$ & $<.0005$ & $<.0005$ & $<.005$ & $<.005$ \\
\hline
\end{tabular}


Table 6

Values of $R \mathrm{~s}$, Beta Coefficients, and Squared $\boldsymbol{t}$ Ratios (for Significant Predictors, in Parentheses) for Animals Versus Fruit and Vegetables and for Variables Associated With Naming-Without-Deadline Response Times (RTs) and With Percentages Correct (\%) and Percentages of Visual-Semantic Errors in Naming With Deadline

\begin{tabular}{|c|c|c|c|}
\hline Variable & RT & $\%$ & Visual-Semantic \\
\hline \multicolumn{4}{|c|}{ Animals } \\
\hline Complexity & $+.44^{* * *}(12.11)$ & $+.37^{*}(5.73)$ & $+.34^{*}(4.26)$ \\
\hline Decomposability & -.08 & $-.10(0.45)$ & $-.04(0.08)$ \\
\hline Contour overlap & $+.32^{*}(6.71)$ & $+.37^{*}(6.12)$ & $+.22(1.99)$ \\
\hline Imageability & $-.29^{*}(6.04)$ & $-.19(1.66)$ & $-.16(1.06)$ \\
\hline Age of acquisition & $+.33^{*}(6.05)$ & $+.13(0.62)$ & $+.17(0.91)$ \\
\hline Name frequency $(\log )$ & +.06 & $+.02(0.02)$ & $+.08(0.18)$ \\
\hline Multiple $R^{2}$ & .53 & .30 & .21 \\
\hline$F$ value & 7.55 & 2.8 & 1.75 \\
\hline Significance $(p)$ & $<.0005$ & $<.05$ & $<.05$ \\
\hline \multicolumn{4}{|c|}{ Fruit and Vegetables } \\
\hline Complexity & +.35 & $+.12(0.23)$ & $+.12(0.18)$ \\
\hline Decomposability & -.19 & $-.09(0.18)$ & $-.16(0.47)$ \\
\hline Contour overlap & +.18 & $+.52^{*}(7.10)$ & $+.48 *(4.86)$ \\
\hline Imageability & $-.75^{*}(7.12)$ & $-.12(0.19)$ & $-.09(0.09)$ \\
\hline Age of acquisition & -.26 & $+.29(0.59)$ & $+.11(0.06)$ \\
\hline Name frequency $(\log )$ & +.14 & $-.06(0.06)$ & $-.11(0.16)$ \\
\hline Multiple $R^{2}$ & .50 & .47 & .33 \\
\hline$F$ value & 2.82 & 2.53 & 1.41 \\
\hline Significance $(p)$ & $<.05$ & n.s. & n.s. \\
\hline
\end{tabular}

tween the categories in terms of the amount of semantic information making up each object concept. For instance, in line with knowledge type theories of category-specific deficits (e.g., Cree \& McRae, 2003; Warrington \& Shallice, 1984), one may propose that there were more visualsemantic errors to living things only because their semantics depends more heavily on visual features than on other types of information, such as how things are used or where they tend to be located. Similarly, there may have been more visual-semantic errors to animals than to fruit and vegetables because their semantics depends more heavily on visual features than on other types of information, such as taste, touch, or function. To address this issue, we used the feature production norms developed by McRae, Cree, Seidenberg, and McNorgan (2005) to assess (1) the extent to which the categories differed in terms of numbers of particular features, corresponding to visual, sensory, functional, encyclopedic, and taxonomic information (as derived from Cree \& McRae, 2003), and (2) whether our findings could be attributed solely to these differences in feature quantity. We found that there were differences in the amount of different kinds of information that made up the different categories. As in other studies, the semantics of living things comprised more visual features than did that of nonliving things, and the semantics of nonliving things comprised more functional features than did that of living things (for a review, see McRae \& Cree, 2002). Moreover, the semantics of animals comprised more visual features corresponding to visual motion, visual parts, and surface properties than did the semantics of fruit and vegetables. Importantly, however, when we partialled out statistically the influence of these numbers of object features on performance, the findings were unaltered (see Appendix D).
These findings suggest that a differential weighting of different types of semantic knowledge may have contributed in an important way to the category effects observed here. However, such an approach on its own is not sufficient to account for the present findings.

Other theories, which also have emphasized statistical regularities in the distribution of properties of items in the different categories, are consistent with the present findings. For instance, accounts that have stressed the importance of correlated features, distinctive features, and visual and semantic similarity-for example, $\mathrm{OUCH}$ (Caramazza et al., 1990), the correlated and distinguishing features account (e.g., Devlin, Gonnerman, Andersen, \& Seidenberg, 1998), HIT (Humphreys \& Forde, 2001), and the CS account (Tyler \& Moss, 2001) — can account for more visual-semantic errors to living things and, possibly, also more errors to animals than to fruit and vegetables. In brief, factors such as increased visual and semantic similarity, more shared and fewer distinctive features, correlate with object class and may lead to poorer object differentiation for living things, particularly under conditions of time pressure. However, we should note here that (1) Cree and McRae (2003) found little evidence of a role for feature correlations in their study, and (2) our additional finding of differences in the proportion of different knowledge types across categories calls into question both $\mathrm{OUCH}$ and CS accounts, which reject a role for different knowledge types in category-specific deficits.

Finally, the central assumption of the domain-specific hypothesis of Caramazza and Shelton (1998) is that concepts are organized by neural systems that have evolved for rapid and efficient identification of animals, fruit and vegetables, and possibly tools. Our data are consistent with this tripartite distinction, and so, at the broadest level of 
description, it could be argued that domain-specific neural constraints may play a role in the organization of conceptual knowledge. However, questions concerning the role of visual processing, how concepts are represented and structured, and how specific properties of objects are related to one another are not addressed by this theory (e.g., Martin \& Caramazza, 2003).

Let us now turn to the other main findings from the present study. First, the premise of this study was that some cases of category differences observed in patient populations may reflect an exaggeration of difficulties observed under normal circumstances. This assumption is supported by the following: (1) Time pressure exaggerated errors found in naming without deadline; (2) category effects were observed; and (3) the same variables that slowed processing under no-deadline conditions also accounted for increased errors in the deadline condition. This suggests that in addition to stimulus factors such as those concerned with object differentiability or confusability, other factors might underlie these effects. What might these factors be?

If response latency and accuracy reflect the time course of processing, external time pressure must engage some kind of control mechanism to shorten this time course. Previous accounts of deadline naming have assumed a particular class of threshold mechanism (e.g., Humphreys et al., 1995; Vitkovitch et al., 1993; for a recent review, see Kello, 2004). For instance, Humphreys et al. (1995) simulated naming under deadline conditions in a computational model, using an interactive activation and competition architecture that had bidirectional excitatory mappings between different levels of visual, semantic, and name representations. They simulated a response deadline by measuring performance at different points in "time" (instantiated as numbers of cycles of the model) prior to activation's reaching a response threshold. In this way, the time course of processing is controlled by gating the flow of information from one level of processing to the next. Different cognitive representations are gradually activated over time, and at some point, particular representations begin to influence subsequent levels of processing. The threshold mechanism plays a role in determining this point in time. An alternative class of threshold mechanism - namely, a rate mechanism - may also be used to explain the effects of a response deadline (Kello, 2004; Kello \& Plaut, 2000, 2003). This mechanism directly influences the growth of activations-for instance, through "compression" of the time course of processing.

The general point here is that in addition to stimulus factors, strategic control factors that involve setting either an activation or a time criterion or controlling the growth of activation may contribute to patient deficits.

Second, the vast majority of errors (visual-semantic errors) were to living things and were associated with visual complexity and visual similarity, and not with other factors, such as imageability or age of acquisition. Thus, difficulties in visual processing appear to be an important source of errors under picture naming with deadline. Moreover, there was a strong association between visual complexity and the category of animals for both naming without deadline and visual-semantic errors in naming with deadline. In contrast, there was an association between visual similarity and visual-semantic errors to fruit and vegetables. We should also note (1) the lack of an association between visual similarity and visual-semantic errors to animals, which is unlikely to be due to a lack of power, given its association with fruit and vegetables, and (2) the low correlation between visual similarity and visual complexity. These findings are consistent with visual complexity's exerting a strong and independent influence on naming under time pressure, where visual complexity is a particularly salient attribute of animals.

Overall, these findings are consistent with theories of category-specific deficits that emphasize the importance of both statistical regularities across concepts and visual factors in producing an impairment for living things (e.g., Cree \& McRae, 2003; HIT, Humphreys \& Forde, 2001). Visual similarity in particular has received much attention in the literature (for reviews, see Cree \& McRae, 2003; Humphreys \& Forde, 2001; Humphreys et al., 1995). Importantly, our findings also suggest that some categoryspecific impairments, particularly those for animals, may reflect an exaggeration of visual-processing difficulties experienced under normal circumstances that are due to visual complexity, rather than to visual similarity (see also Cree \& McRae, 2003). It is likely that more complex objects have a greater number of spatial relations between component object representations (i.e., object parts), which may detrimentally influence the process of matching a description derived from the stimulus to stored object representations when fine-grained visual discriminations are necessary, as in picture naming (cf. Biederman, 1987; Lloyd-Jones \& Luckhurst, 2002a; see Hummel \& Holyoak, 1997, for a discussion of the detrimental effects of complexity in a connectionist architecture similar to that proposed by Hummel \& Biederman, 1992, for object recognition).

Finally, we note that there was an influence of different variables on the overall production of different kinds of naming-to-deadline errors. Visual complexity and visual similarity influenced the production of visual-semantic errors, but not pure semantic errors. In contrast, the production of pure semantic errors was influenced by imageability ${ }^{6}$ and age of acquisition. On first pass, these findings might be taken to support two different sources of error. Visual-semantic errors may have arisen from difficulties in visual processing, whereas pure semantic errors may have arisen from difficulties in semantic or lexical (phonological) processing. However, such an account quickly runs into difficulty.

First, it has been demonstrated that age of acquisition can influence object recognition when it is assessed by object decision (Moore et al., 2004), and object decision may be based on access to visual or semantic information (e.g., Lloyd-Jones \& Luckhurst, 2002b). Similarly, effects of imageability may not be restricted to semantic processing but, rather, may influence visual or lexical processing as well. For instance, there is evidence of topdown influences from semantic onto visual processing (e.g., Dixon et al., 1997; Gauthier, James, Curby, \& Tarr, 2003). Second, there was only a relatively small number of pure semantic errors, and it is possible that they were 
particular cases that reflected the contribution of a number of different factors. For instance, the item that attracted the majority of pure semantic errors was a nut (from the category tools), and the error response was always bolt (see also Vitkovitch et al., 1993). In addition to nut and bolt being semantically related, they also have similar surface texture and color and are frequently encountered in the same visual context. Furthermore, nut is both a homophone (which will boost its name frequency count) and a name strongly associated with the name bolt.

Third and perhaps most important, observing a double dissociation across different error types does not necessitate postulating more than one system as the source of those errors (e.g., Plaut, 1995; Shallice, 1988). As one example, a general mechanism of strategic control that alters the rate of processing can account for a double dissociation in a nonmodular system (e.g., Kello, 2003; Sibley \& Kello, 2005). Thus, in modeling word reading, Kello (2003) has demonstrated how a low rate of processing can produce naming errors that resemble those of surface dyslexia (i.e., more errors to words with irregular spelling-sound correspondences than to regular words and nonwords), whereas a high rate can produce errors that resemble those of phonological dyslexia (i.e., more errors to nonwords than to regular and irregular words). In sum, then, there is only weak evidence of a double dissociation, and we remain equivocal on the source of pure semantic errors.

In conclusion, the findings presented here argue for some category-specific deficits reflecting an exaggeration of difficulties faced under normal circumstances. We have emphasized the importance of statistical regularities in the weighting of different types of semantic knowledge that objects comprise and in the factors that influence visual processing. We have also suggested that in addition to stimulus factors that influence an item's differentiability or confusability, strategic control factors that influence the time course of processing may also be important. Overall, our findings are most consistent with multifactor accounts that propose that the source of category-specific impairments can be at different levels within an interactive semantic system comprising visual, semantic, and lexical representations (e.g., Cree \& McRae, 2003; HIT, Humphreys \& Forde, 2001). Finally, we suggest that with further refinement, the naming-to-deadline technique may prove useful in the development of models of picture naming and category-specific semantic impairments.

\section{AUTHOR NOTE}

We thank three anonymous reviewers and, in particular, Ken McRae, for helpful comments on this article. Correspondence concerning this article should be addressed to T. J. Lloyd-Jones, Department of Psychology, University of Wales Swansea, Singleton Park, Swansea SA2 8PP, Wales (e-mail: t.j.lloyd-jones@swansea.ac.uk).

\section{REFERENCES}

Arguin, M. (2002). Visual processing and the dissociation between biological and man-made categories. In E. M. E. Forde \& G. W. Humphreys (Eds.), Category specificity in brain and mind (pp. 85-110). Hove, U.K.: Psychology Press.

Barry, C., Hirsh, K. W., Johnston, R. A., \& Williams, C. (2001). Age of acquisition, word frequency, and the locus of repetition priming of picture naming. Journal of Memory \& Language, 44, 350-375.

BArry, C., Morrison, C. M., \& Ellis, A. W. (1997). Naming the Snodgrass and Vanderwart pictures: Effects of age of acquisition, frequency and name agreement. Quarterly Journal of Experimental Psychology, 50A, 560-585.

Bates, E., D’Amico, S., Jacobsen, T., Székely, A., Andonova, E., Devescovi, A., ET AL. (2003). Timed picture naming in seven languages. Psychonomic Bulletin \& Review, 10, 344-380.

BIEDERMAN, I. (1987). Recognition-by-components: A theory of human image understanding. Psychological Review, 94, 115-117.

Bub, D., \& Gum, T. (1988). PsychLab manual. Montreal: Montreal Neurological Institute.

Capitani, E., Laiacona, M., Mahon, B., \& Caramazza, A. (2003). What are the facts of semantic category-specific deficits? A critical review of the clinical evidence. Cognitive Neuropsychology, 20, 213-261.

Caramazza, A., Hillis, A. E., Rapp, B. C., \& Romani, C. (1990). The multiple semantics hypothesis: Multiple confusions? Cognitive Neuropsychology, 7, 161-189.

Caramazza, A., \& Mahon, B. (2003). The organization of conceptual knowledge: The evidence from category-specific semantic deficits. Trends in Cognitive Sciences, 7, 354-361.

Caramazza, A., \& Shelton, J. R. (1998). Domain-specific knowledge systems in the brain: The animate-inanimate distinction. Journal of Cognitive Neuroscience, 10, 1-34.

Carrasco, M., \& Seamon, J. G. (1996). Priming impossible figures in the object decision test: The critical importance of perceived stimulus complexity. Psychonomic Bulletin \& Review, 3, 344-351.

Carroll, J. B., \& White, N. M. (1973). Age of acquisition norms for 220 picturable nouns. Journal of Verbal Learning \& Verbal Behavior, 12, 563-576.

Cree, G. S., \& McRae, K. (2003). Analyzing the factors underlying the structure and computation of the meaning of chipmunk, cherry, chisel, cheese, and cello (and many other such concrete nouns). Journal of Experimental Psychology: General, 132, 163-201.

Cutzu, F., \& TARR, M. (1999). Inferring perceptual saliency fields from viewpoint-dependent recognition data. Neural Computation, 11, 1331-1348.

Devlin, J. T., Gonnerman, L. M., Andersen, E. S., \& Seidenberg, M. S. (1998). Category-specific semantic deficits in focal and widespread brain damage: A computational account. Journal of Cognitive Neuroscience, 10, 77-94.

Dixon, M. J., Bub, D. N., \& Arguin, M. (1997). The interaction of object form and object meaning in the identification performance of a patient with category-specific agnosia. Cognitive Neuropsychology, 14, 1085-1130.

Ellis, A. W., \& LAmbon Ralph, M. A. (2000). Age of acquisition effects in adult lexical processing reflect loss of plasticity in maturing systems: Insights from connectionist networks. Journal of Experimental Psychology: Learning, Memory, \& Cognition, 26, 1103-1123.

Ellis, A. W., \& Morrison, C. M. (1998). Real age of acquisition effects in lexical retrieval. Journal of Experimental Psychology: Learning, Memory, \& Cognition, 24, 515-523.

Farah, M. J., \& McClelland, J. L. (1991). A computational model of semantic memory impairment: Modality specificity and emergent category specificity. Journal of Experimental Psychology: General, 120, 339-357.

Farah, M. J., McMullen, P. A., \& Meyer, M. M. (1991). Can recognition of living things be selectively impaired? Neuropsychologia, 29, 185-193.

Farah, M. J., \& Wallace, M. A. (1992). Semantically-bound anomia: Implications for the neural implementation of naming. Neuropsychologia, 30, 609-621.

Forde, E. M. E., \& Humphreys, G. W. (EDs.) (2002). Category specificity in brain and mind. Hove, U.K.: Psychology Press.

Funnell, E., \& Sheridan, J. (1992). Categories of knowledge? Unfamiliar aspects of living and nonliving things. Cognitive Neuropsychology, 9, 135-153.

Garrard, P., Lambon Ralph, M. A., Hodges, J. R., \& Patterson, K. (2001). Prototypicality, distinctiveness, and intercorrelation: Analyses of the semantic attributes of living and nonliving concepts. Cognitive Neuropsychology, 18, 125-174. 
Gauthier, I., James, T. W., Curby, K. M., \& Tarr, M. J. (2003). The influence of conceptual knowledge on visual discrimination. Cognitive Neuropsychology, 20, 507-523.

GERLACH, C. (2001). Structural similarity causes different category-effects depending on task characteristics. Neuropsychologia, 39, 895-900.

GhySELinck, M., Custers, R., \& BrysBaerT, M. (2004). The effect of age of acquisition in visual word processing: Further evidence for the semantic hypothesis. Journal of Experimental Psychology: Learning, Memory, \& Cognition, 30, 550-554.

Gilhooly, K. J. (1984). Word age-of-acquisition and residence time in lexical memory as factors in word naming. Current Psychological Research \& Reviews, 3, 24-31.

Gilhooly, K. J., \& Logie, R. H. (1980). Age-of-acquisition, imagery, concreteness, familiarity, and ambiguity measures for 1,944 words. Behavior Research Methods \& Instrumentation, 12, 395-427.

Glaser, W. R. (1992). Picture naming. Cognition, 42, 61-105.

Gonnerman, L. M., Andersen, E. S., Devlin, J. T., Kempler, D., \& SeIDENBERG, M. S. (1997). Double dissociation of semantic categories in Alzheimer's disease. Brain \& Language, 57, 254-279.

Gordon, B. (1997). Models of naming. In H. Goodglass \& A. Wingfield (Eds.), Anomia: Neuroanatomical and cognitive correlates (pp. 3164). San Diego: Academic Press.

Hart, J., Berndt, R. S., \& Caramazza, A. (1985). Category-specific naming deficit following cerebral infarction. Nature, 316, 439-440.

Hayward, W. G., TARr, M. J., \& Corderoy, A. K. (1999). Recognizing silhouettes and shaded images across depth rotation. Perception, $\mathbf{2 8}$ 1197-1215.

Hillis, A. E., \& Caramazza, A. (1991). Category-specific naming and comprehension impairment: A double dissociation. Brain, 114, 2081-2094.

Howell, D. C. (1997). Statistical methods in psychology (4th ed.). Belmont, CA: Duxbury Press.

Hummel, J., \& Biederman, I. (1992). Dynamic binding in a neural network for shape recognition. Psychological Review, 99, 480-517.

Hummel, J., \& Holyoak, K. J. (1997). Distributed representations of structure: A theory of analogical access and mapping. Psychological Review, 104, 427-466.

Humphreys, G. W., \& FordE, E. M. E. (2001). Hierarchies, similarity, and interactivity in object recognition: "Category-specific" neuropsychological deficits. Behavioural \& Brain Sciences, 24, 453-476.

Humphreys, G. W., Lamote, C., \& Lloyd-Jones, T. J. (1995). An interactive activation approach to object processing: Effects of structural similarity, name frequency and task in normality and pathology. Memory, 3, 535-586.

Humphreys, G. W., Riddoch, M. J., \& Forde, E. M. E. (2001). The principle of target-competitor differentiation in object recognition and naming (and its role in category effects in normality and pathology). In E. M. E. Forde \& G. W Humphreys (Eds.), Category specificity in brain and mind (pp. 51-78). Hove, U.K.: Psychology Press.

HumPhreys, G. W., Riddoch, M. J., \& Quinlan, P. T. (1988). Cascade processes in picture identification. Cognitive Neuropsychology, 5, 67-103.

Izura, C., \& Ellis, A. W. (2004). Age of acquisition effects in translation judgment tasks. Journal of Memory \& Language, 50, 165-181.

Johnson, C. J., Paivio, A., \& Clark, J. M. (1996). Cognitive components of picture naming. Psychological Bulletin, 120, 113-139.

Kello, C. T. (2003). The emergence of a double dissociation in the modulation of a single control parameter in a nonlinear dynamical system. Cortex, 39, 132-134.

Kello, C. T. (2004). Control over the time course of cognition in the tempo-naming task. Journal of Experimental Psychology: Human Perception \& Performance, 30, 942-955.

Kello, C. T., \& Plaut, D. C. (2000). Strategic control in word reading: Evidence from speeded responding in the tempo-naming task. Journal of Experimental Psychology: Learning, Memory, \& Cognition, 26, 719-750.

Kello, C. T., \& Plaut, D. C. (2003). Strategic control over rate of processing in word reading: A computational investigation. Journal of Memory \& Language, 48, 207-232.

Laiacona, M., \& CAPITANI, E. (2001). A case of prevailing deficit of nonliving categories or a case of prevailing sparing of living categories? Cognitive Neuropsychology, 18, 37-90.

Lambon Ralph, M. A., Howard, D., Nightingale, G., \& Ellis, A. W.
(1998). Are living and non-living category-specific deficits causally linked to impaired perceptual or associative knowledge? Evidence from a category-specific double dissociation. NeuroCase, 4, 311-338.

Laws, K. R., \& Gale, T. M. (2002). Category-specific naming and the 'visual' characteristics of line drawn stimuli. Cortex, 38, 7-21.

Laws, K. R., \& Neve, C. (1999). A 'normal' category-specific advantage for naming living things. Neuropsychologia, 37, 1263-1269.

LEVELT, W. J. M. (1989). Speaking: From intention to articulation. Cambridge, MA: MIT Press.

LeVelt, W. J. M., Roelofs, A., \& Meyer, A. S. (1999). A theory of lexical access in speech production. Behavioural \& Brain Sciences, 22, 1-75.

Lloyd-Jones, T. J., \& Humphreys, G. W. (1997a). Categorizing chairs and naming pears: Category differences in object processing as a function of task and priming. Memory \& Cognition, 25, 606-624.

Lloyd-Jones, T. J., \& Humphreys, G. W. (1997b). Perceptual differentiation as a source of category effects in object processing: Evidence from naming and object decision. Memory \& Cognition, 25, 18-35.

Lloyd-Jones, T. J., \& LUCKHURST, L. (2002a). Effects of plane rotation, task, and visual complexity on recognition of familiar and chimeric objects. Memory \& Cognition, 30, 499-510.

Lloyd-Jones, T. J., \& LUCKHURST, L. (2002b). Outline shape is a mediator of object recognition that is particularly important for living things. Memory \& Cognition, 30, 489-498.

LonG, G. M., \& Wurst, S. A. (1984). Complexity effects on RT measures of visual persistence: Evidence for peripheral and central contributions. American Journal of Psychology, 97, 537-561.

LORCH, R. F., \& MYERS, J. L. (1990). Regression analysis of repeated measures data in cognitive research. Journal of Experimental Psychology: Learning, Memory, \& Cognition, 16, 149-157.

Marcel, A. J., \& Patterson, K. E. (1978). Word recognition and production: Reciprocity in clinical and normal studies. In J. Requin (Ed.), Attention and performance VII (pp. 209-225). Hillsdale, NJ: Erlbaum.

Martin, A., \& Caramazza, A. (2003). Neuropsychological and neuroimaging perspectives on conceptual knowledge: An introduction. Cognitive Neuropsychology, 20, 195-212.

McKenna, P., \& WarRington, E. K. (1978). Category-specific naming preservation: A single case study. Journal of Neurology, Neurosurgery, \& Psychiatry, 41, 571-574.

McRAe, K., \& Cree, G. S. (2002). Factors underlying category-specific semantic impairments. In E. M. E. Forde \& G. W. Humphreys (Eds.), Category specificity in brain and mind (pp. 211-251). Hove, U.K.: Psychology Press.

McRae, K., Cree, G. S., Seidenberg, M. S., \& McNorgan, C. (2005). Semantic feature production norms for a large set of living and nonliving things. Behavior Research Methods, 37, 547-559.

Moore, V., Smith-Spark, J. H., \& Valentine, T. (2004). The effects of age of acquisition on object perception. European Journal of Cognitive Psychology, 16, 417-439.

Morrison, C. M. (2003). Interpret with caution: Multicollinearity in multiple regression of cognitive data. Perceptual \& Motor Skills, 97, 80-82.

Morrison, C. M., Ellis, A. W., \& Quinlan, P. T. (1992). Age of acquisition, not word frequency, affects object naming, not object recognition. Memory \& Cognition, 20, 705-714.

NicKels, L. (1995). Getting it right? Using aphasic naming errors to evaluate theoretical models of spoken word production. Language \& Cognitive Processes, 10, 13-45.

NicKELS, L. (1997). Spoken word production and its breakdown in aphasia. Hove, U.K.: Psychology Press.

Nickels, L., \& HowARD, D. (1994). A frequent occurrence? Variables affecting the production of semantic errors in aphasic naming. Cognitive Neuropsychology, 11, 289-320.

Plaut, D. C. (1995). Double dissociation without modularity: Evidence from connectionist neuropsychology. Journal of Clinical \& Experimental Neuropsychology, 17, 291-321.

Plaut, D. C. (1997). Structure and function in the lexical system: Insights from distributed models of word reading and lexical decision. Language \& Cognitive Processes, 12, 765-805.

Plaut, D. C., \& Shallice, T. (1993). Deep dyslexia: A case study of connectionist neuropsychology. Cognitive Neuropsychology, 10, 377-500.

Rosch, E. (1975). Cognitive representations of semantic categories. Journal of Experimental Psychology: General, 104, 192-233. 
Saffran, E. J., \& Schwartz, M. F. (1994). Of cabbages and things: Semantic memory from a neuropsychological point of view-a tutorial review. In C. Umiltà \& M. Moscovitch (Eds.), Attention and performance $X V$ : Conscious and nonconscious information processing (pp. 507-536). Cambridge, MA: MIT Press, Bradford Books.

SAmson, D., \& Pillon, A. (2003). A case of impaired knowledge for fruit and vegetables. Cognitive Neuropsychology, 20, 373-401.

Sartori, G., Job, R., \& Coltheart, M. (1993). The organization of object knowledge: Evidence from neuropsychology. In D. E. Meye $\&$ S. Kornblum (Eds.), Attention and performance XIV: Synergies in experimental psychology, artificial intelligence, and cognitive neuroscience (pp. 451-465). Cambridge, MA: MIT Press.

Schriefers, H., Meyer, A. S., \& Levelt, W. J. M. (1990). Exploring the time course of lexical access in language production: Picture-word interference studies. Journal of Memory \& Language, 29, 86-102.

Shallice, T. (1988). From neuropsychology to mental structure. Cambridge: Cambridge University Press.

Sibley, D. E., \& Kello, C. T. (2005). A computational exploration of double dissociations: Modes of processing instead of components of processing. Cognitive Systems Research, 6, 61-69.

Silveri, M. C., \& Gainotti, G. (1988). Interaction between vision and language in category-specific semantic impairment. Cognitive Neuropsychology, 5, 677-709.

Snodgrass, J. G., \& McCullough, B. (1986). The role of visual similarity in picture categorization. Journal of Experimental Psychology: Learning, Memory, \& Cognition, 12, 147-154.

SnOdgrass, J. G., \& VANDERWART, M. (1980). Standardized set of 260 pictures: Norms of name agreement, usage agreement, word familiarity, and visual complexity. Journal of Experimental Psychology: Human Learning \& Memory, 6, 174-215.

SnOdGrass, J. G., \& Yuditsky, T. (1996). Naming times for the Snodgrass and Vanderwart pictures. Behavior Research Methods, Instruments, \& Computers, 28, 516-536.

Strain, E., Patterson, K., \& Seidenberg, M. S. (1995). Semantic effects in single-word naming. Journal of Experimental Psychology: Learning, Memory, \& Cognition, 21, 1140-1154.

TAвACHNick, B. G., \& Fidell, L. S. (1996). Using multivariate statistics (3rd ed.). New York: HarperCollins.

Toothaker, L. E. (1993). Multiple comparison procedures. Newbury Park, CA: Sage.

Tranel, D., Logan, C. G., Frank, R. J., \& Damasio, A. R. (1997) Explaining category-related effects in the retrieval of conceptual and lexical knowledge for concrete entities: Operationalization and analysis of factors. Neuropsychologia, 35, 1329-1339.

Tyler, L. K., \& Moss, H. E. (2001). Towards a distributed account of conceptual knowledge. Trends in Cognitive Sciences, 5, 244-252.

van Hell, J. G., \& DE Groot, A. M. B. (1998). Disentangling context availability and concreteness in lexical decision and word translation. Quarterly Journal of Experimental Psychology, 51A, 41-63.

VERnON, D., \& Lloyd-Jones, T. J. (2003). The role of colour in implicit and explicit memory performance. Quarterly Journal of Experimental Psychology, 5, 779-803.

Vitkovitch, M., \& Humphreys, G. W. (1991). Perseverant responding in speeded picture naming: It's in the links. Journal of Experimental Psychology: Learning, Memory, \& Cognition, 17, 664-680.

Vitkovitch, M., Humphreys, G. W., \& Lloyd-Jones, T. J. (1993). On naming a giraffe a zebra: Picture naming errors across different object categories. Journal of Experimental Psychology: Learning, Memory, \& Cognition, 19, 243-259.
Vitkovitch, M., \& Tyrrell, L. (1995). Sources of disagreement in object naming. Quarterly Journal of Experimental Psychology, 48A, 822-848.

WARrington, E. K. (1975). The selective impairment of semantic memory. Quarterly Journal of Experimental Psychology, 27, 635-657.

Warrington, E. K., \& Shallice, T. (1984). Category-specific semantic impairments. Brain, 107, 829-854.

Zevin, J. D., \& Seidenberg, M. S. (2002). Age of acquisition effects in word reading and other tasks. Journal of Memory \& Language, 47, 1-29.

\section{NOTES}

1. Several models have proposed a number of additional postsemantic stages of representation involved in name selection and production (e.g., Levelt, 1989; Levelt, Roelofs, \& Meyer, 1999). For clarity, we will not develop them here.

2. Snodgrass and Yuditsky's (1996) age-of-acquisition ratings were missing for six items. We replaced these with the mean value of items in the same living/nonliving or animal/fruit-and-vegetable category (cf. Tabachnick \& Fidell, 1996). If we drop these items altogether, the results are unaltered.

3. We also examined whether the deadline increased relative error proportions (i.e., the proportion of each type of error over the total number of errors). The deadline did not produce a disproportionate increase in visual-semantic errors (the majority error type), although there was some evidence of a disproportionate increase in pure semantic errors (i.e., when the living vs. nonliving things category was analyzed, but not when living things were subdivided into animals vs. fruit and vegetables). This tentatively suggests that the processes mediating pure semantic errors may be particularly vulnerable to time pressure.

4. Following Snodgrass and Yuditsky (1996, pp. 519-520), we examined both uncorrected RTs and RTs corrected in order to take account of the positive skew of RT distributions. We found a very high correlation $(r=.99)$ between untrimmed and trimmed means (in the latter case, we eliminated long RTs to each item by using a 2.5 standard deviation cutoff procedure). Moreover, the findings were the same for both dependent variables. Therefore, we will report results only for trimmed means.

5. More precisely, (1) across all items, for percentage correct and for pure semantic errors as dependent variables, when age of acquisition was omitted, name frequency became significant; (2) for nonliving items, for pure semantic errors as the dependent variable, when name frequency was omitted, age of acquisition became significant; and (3) across all items (and with additional variables in the analysis; see Appendix A), for pure semantic errors, when name frequency was omitted, age of acquisition became significant.

6 . The production of pure semantic errors was influenced by imageability; greater ease in imageability corresponded to an increase in likelihood that such an error would be produced. If imageability ratings reflect the richness of a semantic representation, as some have suggested (e.g., Plaut \& Shallice, 1993; van Hell \& de Groot, 1998), or, perhaps, the speed with which meaning becomes available (e.g., Plaut, 1997), we might have predicted the opposite effect-namely, that higher imageability objects would be less harmed by degradation under time pressure. However, this was not the case. Rather, it may be that the effects of imageability on semantic processing observed here are analogous to the effects of visual complexity on visual processing: Increased imageability may correspond to increased semantic complexity, which may be harmful when fine-grained differentiation between object concepts is required. We thank an anonymous reviewer for this suggestion. 
APPENDIXA

In Table A1, we present the original regression analyses on all items, but with the inclusion of a number of additional variables - namely, image agreement, familiarity, number of syllables, and name agreement (for reasons of space, we do not provide all the other regression analyses with these additional variables, but they are available from the authors upon request). The findings on the whole remain unaltered.

In addition, two of the new variables had effects of their own. First, image agreement was associated with both accuracy and visual-semantic errors in naming with deadline. Image agreement has been localized by Barry et al. (1997) in the process of retrieving a visual object representation, whereby the closer the picture is to one's mental image of the object, the less time that is required for naming. In the present study, image agreement did not correlate significantly with any other visual variables; however, there were significant correlations with name frequency $(r=-.172)$ and name agreement $(r=.163)$. Second, name agreement was associated with RTs in naming without deadline, and both accuracy and visual-semantic errors in naming with deadline. Recent research has suggested that name agreement, too, may have its locus at the level of retrieving a visual representation or, alternatively, at the level of name retrieval (Barry et al., 1997; Vitkovitch \& Tyrrell, 1995). As Barry et al. (1997) state: "For items where the effect [of name agreement] arises as a result of competing responses, it has its locus at or around the level of structural descriptions; but for items where the effect arises as a result of competing correct responses, it has its locus post-semantically" (p. 574). Consistent with these ideas, in this study, name agreement was significantly correlated with visual complexity $(r=-.174)$, image agreement $(r=$ $.163)$, imageability $(r=.184)$, and age of acquisition $(r=-.162)$.

Table A1

Values of $R \mathrm{~s}$, Standardized Beta Coefficients, and Squared $\boldsymbol{t}$ Ratios (in Parentheses) for All Items, for Significant Variables Associated With Naming-Without-Deadline Response Times (RTs) and With Percentages Correct and Percentages of Visual-Semantic, Pure Semantic, and Pure Visual Errors in Naming With Deadline

\begin{tabular}{|c|c|c|c|c|c|}
\hline \multirow[b]{2}{*}{ Variable } & \multirow[b]{2}{*}{ RT } & \multirow[b]{2}{*}{$\%$ Correct } & \multicolumn{3}{|c|}{ Error Type } \\
\hline & & & Visual-Semantic & Semantic & Visual \\
\hline $\begin{array}{l}\text { Complexity } \\
\text { Decomposability }\end{array}$ & $+.22^{*}(6.39)$ & & $+.14^{\mathrm{a}}(3.61)$ & & \\
\hline Contour overlap & $+.15^{*}(5.16)$ & $-.18^{* *}(7.35)$ & $+.17^{*}(4.04)$ & & \\
\hline Imageability & $-.21^{* *}(9.75)$ & & & $+.20^{*}(6.42)$ & \\
\hline $\begin{array}{l}\text { Age of acquisition } \\
\text { Name frequency (log) }\end{array}$ & $+.20^{*}(6.06)$ & $-.21^{*}(6.46)$ & & $+.17^{\mathrm{a}}(4.04)$ & $+.23^{*}(5.93)$ \\
\hline $\begin{array}{l}\text { Living/nonliving } \\
\text { Image agreement } \\
\text { Familiarity } \\
\text { Syllables }\end{array}$ & $-.16^{*}(4.02)$ & $\begin{array}{l}+.30^{* * * *}(13.18) \\
+.17^{*}(6.36)\end{array}$ & $\begin{array}{l}-.43^{* * *}(26.26) \\
-.15^{*}(5.42)\end{array}$ & $+.25^{*}(6.52)$ & \\
\hline Name agreement & $-.16^{*}(5.40)$ & $+.16^{*}(5.10)$ & $-.15^{*}(4.30)$ & & \\
\hline Multiple $R^{2}$ & .39 & .35 & .38 & .13 & .11 \\
\hline$F$ value & 11.03 & 9.54 & 10.98 & 2.69 & 2.15 \\
\hline Significance $(p)$ & $<.0005$ & $<.0005$ & $<.0005$ & $<.005$ & $<.05$ \\
\hline
\end{tabular}

Note-The ratings for image agreement, familiarity, and name agreement were taken from Snodgrass and Vanderwart (1980). The number of syllables was calculated by the experimenters. ${ }^{a} p=.06 .{ }^{*} p<.05 . \quad{ }^{* *} p<$ $.01 .{ }^{* * *} p<.0005$. 
APPENDIX B

Ratings of Complexity (COM), Decomposability (DEC), Contour Overlap (CO), Imageability (IMAG), Age of Acquisition (AA), Log Name Frequency $(\log N \mathrm{~F})$, and Name Agreement (NA, Derived From the Present Study) for 204 Pictures From Snodgrass and Vanderwart (1980)

\begin{tabular}{|c|c|c|c|c|c|c|c|}
\hline Picture & $\mathrm{COM}$ & DEC & $\mathrm{CO}$ & IMAG & AA & $\log \mathrm{NF}$ & NA \\
\hline \multicolumn{8}{|c|}{ Living } \\
\hline Alligator & 4.08 & 5.71 & 13.48 & 5.96 & 4.86 & 0.00 & 96.7 \\
\hline Ant & 3.92 & 11.26 & 17.30 & 5.93 & 2.74 & 0.60 & 71.4 \\
\hline Apple & 1.82 & 3.12 & 22.14 & 6.70 & 2.55 & 1.26 & 100.0 \\
\hline Artichoke & 3.72 & 6.47 & 22.34 & 3.70 & 6.28 & 0.00 & 70.0 \\
\hline Asparagus & 3.32 & 3.24 & 8.17 & 4.93 & 6.03 & 0.00 & 80.0 \\
\hline Banana & 1.32 & 2.15 & 17.92 & 6.78 & 2.76 & 0.60 & 100.0 \\
\hline Bear & 3.68 & 7.74 & 21.52 & 6.04 & 3.65 & 1.28 & 100.0 \\
\hline Bee & 4.75 & 10.41 & 26.15 & 6.33 & 3.53 & 0.85 & 60.7 \\
\hline Beetle & 3.65 & 10.74 & 21.49 & 5.26 & 5.32 & 0.70 & 92.9 \\
\hline Butterfly & 4.25 & 9.94 & 10.93 & 6.07 & 3.58 & 0.70 & 100.0 \\
\hline Camel & 3.75 & 9.06 & 19.18 & 6.19 & 4.89 & 0.90 & 100.0 \\
\hline Carrot & 2.95 & 2.74 & 9.36 & 6.22 & 3.16 & 0.48 & 100.0 \\
\hline Cat & 3.25 & 8.03 & 13.93 & 6.37 & 2.50 & 1.61 & 100.0 \\
\hline Caterpillar & 3.58 & 10.47 & 27.38 & 5.59 & 4.26 & 0.30 & 89.7 \\
\hline Celery & 4.25 & 4.32 & 16.11 & 5.30 & 5.00 & 0.48 & 79.2 \\
\hline Cherry & 1.60 & 2.09 & 20.18 & 6.15 & 3.79 & 0.78 & 90.0 \\
\hline Chicken & 3.48 & 7.53 & 20.11 & 6.37 & 3.13 & 1.48 & 96.6 \\
\hline Corn & 3.58 & 7.47 & 10.39 & 5.04 & 3.50 & 1.38 & 95.2 \\
\hline Cow & 3.85 & 11.79 & 17.74 & 6.38 & 3.11 & 1.34 & 93.3 \\
\hline Deer & 3.55 & 12.00 & 22.03 & 6.00 & 3.98 & 0.78 & 100.0 \\
\hline Dog & 3.38 & 9.47 & 17.04 & 6.54 & 2.23 & 1.85 & 100.0 \\
\hline Donkey & 3.35 & 10.74 & 19.23 & 6.00 & 4.35 & 0.95 & 93.3 \\
\hline Duck & 3.32 & 7.59 & 15.75 & 5.96 & 2.93 & 0.60 & 100.0 \\
\hline Eagle & 4.18 & 8.00 & 13.07 & 6.31 & 5.08 & 0.85 & 66.7 \\
\hline Elephant & 4.12 & 10.65 & 10.18 & 6.35 & 3.66 & 0.78 & 100.0 \\
\hline Fly & 4.10 & 10.32 & 21.90 & 5.42 & 3.63 & 1.43 & 86.2 \\
\hline Fox & 4.02 & 10.00 & 17.02 & 5.88 & 4.00 & 1.00 & 100.0 \\
\hline Frog & 3.42 & 7.32 & 21.37 & 5.77 & 3.48 & 0.60 & 100.0 \\
\hline Giraffe & 4.65 & 10.29 & 9.83 & 6.00 & 4.21 & 0.00 & 96.7 \\
\hline Goat & 3.18 & 10.35 & 17.51 & 5.65 & 4.50 & 1.08 & 96.7 \\
\hline Gorilla & 3.62 & 9.68 & 16.66 & 6.00 & 4.50 & 0.30 & 96.6 \\
\hline Grapes & 3.00 & 16.76 & 11.17 & 6.19 & 3.50 & 0.90 & 100.0 \\
\hline Grasshopper & 4.40 & 8.79 & 16.74 & 4.89 & 4.28 & 0.00 & 92.3 \\
\hline Horse & 3.82 & 10.15 & 11.77 & 6.52 & 3.53 & 1.93 & 96.7 \\
\hline Kangaroo & 3.98 & 10.53 & 9.87 & 8.85 & 4.30 & 0.00 & 100.0 \\
\hline Lemon & 1.85 & 1.41 & 22.00 & 6.22 & 3.60 & 1.11 & 96.7 \\
\hline Leopard & 4.28 & 9.85 & 13.05 & 5.67 & 4.95 & 0.85 & 80.0 \\
\hline Lettuce & 3.48 & 3.53 & 24.03 & 5.85 & 4.24 & 0.78 & 89.3 \\
\hline Lion & 4.30 & 9.26 & 13.98 & 6.26 & 3.75 & 0.90 & 96.7 \\
\hline Monkey & 3.90 & 8.00 & 12.20 & 6.00 & 3.84 & 0.95 & 100.0 \\
\hline Mouse & 3.28 & 8.38 & 14.25 & 5.96 & 3.35 & 0.90 & 100.0 \\
\hline Mushroom & 3.12 & 2.82 & 11.47 & 6.19 & 4.45 & 0.70 & 100.0 \\
\hline Onion & 2.85 & 3.12 & 18.86 & 6.00 & 4.08 & 0.95 & 71.4 \\
\hline Orange & 2.12 & 1.82 & 25.50 & 6.30 & 3.23 & 1.43 & 93.1 \\
\hline Ostrich & 3.70 & 6.47 & 16.87 & 5.30 & 5.55 & 0.30 & 93.3 \\
\hline Owl & 4.22 & 7.18 & 11.00 & 5.74 & 4.08 & 0.48 & 85.7 \\
\hline Peach & 2.55 & 1.85 & 33.64 & 5.93 & 3.74 & 0.48 & 100.0 \\
\hline Peacock & 4.75 & 7.47 & 7.53 & 5.93 & 4.90 & 0.48 & 56.0 \\
\hline Peanut & 2.82 & 1.18 & 15.13 & 5.63 & 3.55 & 0.48 & 96.7 \\
\hline Pear & 1.15 & 2.53 & 18.23 & 6.00 & 3.68 & 0.30 & 92.0 \\
\hline Penguin & 2.82 & 7.06 & 16.19 & 6.37 & 4.74 & 0.60 & 100.0 \\
\hline Pepper & 2.48 & 3.68 & 26.24 & 4.74 & 4.78 & 0.85 & 88.5 \\
\hline Pig & 3.00 & 8.76 & 18.81 & 6.22 & 3.15 & 1.26 & 100.0 \\
\hline Pineapple & 4.35 & 7.24 & 21.75 & 6.37 & 4.89 & 0.30 & 100.0 \\
\hline Potato & 2.20 & 1.82 & 19.95 & 5.92 & 3.64 & 1.04 & 85.2 \\
\hline Pumpkin & 2.60 & 4.91 & 10.39 & 5.67 & 4.00 & 0.30 & 89.3 \\
\hline Rabbit & 3.28 & 8.32 & 16.90 & 5.92 & 2.80 & 1.04 & 100.0 \\
\hline Raccoon & 4.40 & 10.68 & 14.41 & 4.58 & 5.21 & 0.00 & 76.9 \\
\hline Rhino & 4.15 & 11.59 & 11.60 & 5.54 & 5.15 & 0.00 & 100.0 \\
\hline Rooster & 4.12 & 11.09 & 13.75 & 4.21 & 4.16 & 0.00 & 70.0 \\
\hline Sheep & 3.80 & 8.06 & 19.11 & 6.13 & 3.60 & 1.30 & 50.0 \\
\hline Skunk & 4.72 & 7.09 & 10.96 & 4.92 & 4.33 & 0.00 & 78.6 \\
\hline Spider & 3.68 & 10.15 & 21.71 & 6.25 & 3.38 & 0.60 & 100.0 \\
\hline Squirrel & 3.75 & 7.97 & 10.80 & 5.79 & 3.89 & 0.60 & 100.0 \\
\hline
\end{tabular}




\begin{tabular}{|c|c|c|c|c|c|c|c|}
\hline \multicolumn{8}{|c|}{ APPENDIX B (Continued) } \\
\hline Picture & $\mathrm{COM}$ & DEC & $\mathrm{CO}$ & IMAG & AA & $\log N F$ & NA \\
\hline Strawberry & 3.38 & 3.59 & 26.59 & 6.54 & 3.68 & 0.48 & 93.1 \\
\hline Swan & 3.05 & 4.29 & 6.57 & 6.25 & 4.30 & 0.70 & 93.1 \\
\hline Tiger & 4.62 & 10.15 & 16.35 & 6.07 & 3.95 & 0.60 & 74.1 \\
\hline Tomato & 1.98 & 2.15 & 23.54 & 6.52 & 3.47 & 0.85 & 89.3 \\
\hline Turtle & 3.62 & 9.06 & 14.25 & 5.78 & - & 0.00 & 100.0 \\
\hline Watermelon & 2.28 & 3.94 & 10.86 & 5.85 & 4.08 & 0.00 & 100.0 \\
\hline Zebra & 4.55 & 8.09 & 19.41 & 6.11 & - & 0.00 & 100.0 \\
\hline \multicolumn{8}{|c|}{ Nonliving } \\
\hline Airplane & 3.50 & 7.56 & 11.39 & 6.30 & 3.49 & 0.60 & 100.0 \\
\hline Ashtray & 2.25 & 4.35 & 9.18 & 5.22 & 4.95 & 0.78 & 96.3 \\
\hline Axe & 2.48 & 2.26 & 25.00 & 5.89 & 4.97 & 0.85 & 100.0 \\
\hline Baby carriage & 3.42 & 8.32 & 11.94 & 4.33 & 4.10 & 0.00 & 96.7 \\
\hline Ball & 2.28 & 4.97 & 16.14 & 6.22 & 2.03 & 1.97 & 100.0 \\
\hline Balloon & 1.55 & 2.44 & 10.66 & 6.41 & 2.38 & 0.48 & 100.0 \\
\hline Barn & 3.30 & 8.68 & 5.46 & 5.85 & 4.15 & 1.00 & 48.3 \\
\hline Baseball bat & 1.20 & 2.82 & 5.05 & 5.33 & 3.78 & 0.00 & 92.9 \\
\hline Basket & 4.30 & 3.47 & 9.64 & 5.44 & 4.16 & 1.26 & 100.0 \\
\hline Bed & 2.85 & 6.03 & 6.34 & 6.37 & 2.42 & 2.39 & 100.0 \\
\hline Bell & 2.62 & 4.53 & 12.06 & 5.74 & 3.60 & 1.45 & 100.0 \\
\hline Belt & 2.00 & 3.56 & 9.78 & 5.81 & 3.95 & 1.30 & 93.3 \\
\hline Bicycle & 3.85 & 10.97 & 9.62 & 6.44 & 3.74 & 1.26 & 100.0 \\
\hline Blouse & 3.10 & 7.56 & 11.28 & 5.41 & 4.87 & 0.95 & 43.3 \\
\hline Book & 2.10 & 3.53 & 10.94 & 6.07 & 2.79 & 2.43 & 100.0 \\
\hline Boot & 2.45 & 3.68 & 8.45 & 8.52 & 3.75 & 0.95 & 90.0 \\
\hline Bottle & 1.68 & 1.94 & 14.35 & 6.26 & 3.58 & 1.91 & 100.0 \\
\hline Bowl & 1.82 & 1.47 & 9.32 & 5.48 & 2.89 & 1.43 & 100.0 \\
\hline Box & 1.38 & 3.44 & 14.06 & 6.19 & 2.69 & 1.59 & 100.0 \\
\hline Broom & 2.42 & 3.00 & 9.62 & 5.96 & 3.73 & 0.78 & 86.2 \\
\hline Brush & 2.82 & 2.94 & 11.89 & 5.74 & 3.08 & 1.11 & 100.0 \\
\hline Bus & 3.95 & 19.71 & 11.11 & 6.44 & 3.10 & 1.81 & 96.7 \\
\hline Button & 2.02 & 2.76 & 16.95 & 5.85 & - & 1.18 & 96.7 \\
\hline Candle & 2.48 & 4.50 & 7.49 & 6.37 & 4.10 & 0.90 & 100.0 \\
\hline Cannon & 3.92 & 8.21 & 5.94 & 5.48 & - & 0.48 & 82.1 \\
\hline Cap & 2.18 & 3.41 & 12.68 & 5.07 & 3.61 & 1.43 & 75.9 \\
\hline Car & 4.05 & 10.94 & 15.90 & 6.41 & 2.73 & 2.44 & 100.0 \\
\hline Chain & 2.55 & 9.41 & 21.90 & 5.04 & 4.73 & 1.52 & 89.3 \\
\hline Chair & 2.05 & 9.76 & 8.34 & 6.52 & 2.92 & 2.02 & 100.0 \\
\hline Chisel & 3.12 & 3.79 & 24.05 & 4.85 & 7.03 & 0.30 & 71.4 \\
\hline Church & 3.28 & 18.21 & 6.11 & 6.04 & 3.85 & 2.20 & 100.0 \\
\hline Cigar & 3.58 & 2.47 & 18.88 & 5.63 & 5.82 & 1.11 & 77.3 \\
\hline Cigarette & 2.25 & 3.50 & 15.04 & 8.89 & 4.78 & 1.69 & 93.1 \\
\hline Clock & 2.68 & 7.56 & 12.67 & 6.23 & 3.47 & 1.56 & 100.0 \\
\hline Clothespin & 2.82 & 3.82 & 17.96 & 2.62 & 4.95 & 0.00 & 100.0 \\
\hline Clown & 4.50 & 10.65 & 14.06 & 5.69 & 3.23 & 0.48 & 85.7 \\
\hline Coat & 2.55 & 7.65 & 7.55 & 5.54 & 3.47 & 1.71 & 96.7 \\
\hline Comb & 2.38 & 4.65 & 16.68 & 5.69 & 3.10 & 0.60 & 100.0 \\
\hline Couch & 2.28 & 8.62 & 12.41 & 5.31 & 3.63 & 0.95 & 96.7 \\
\hline Cup & 1.78 & 2.53 & 9.92 & 6.38 & 2.68 & 1.77 & 100.0 \\
\hline Desk & 3.05 & 12.47 & 13.68 & 6.08 & 3.92 & 1.91 & 80.0 \\
\hline Doll & 4.12 & 13.47 & 8.71 & 5.81 & 2.46 & 1.23 & 70.0 \\
\hline Door & 3.22 & 6.21 & 15.15 & 5.96 & 2.55 & 2.52 & 86.7 \\
\hline Doorknob & 2.68 & 4.68 & 9.20 & 5.69 & 3.85 & 0.00 & 93.1 \\
\hline Dress & 2.65 & 3.71 & 11.44 & 5.77 & 3.32 & 1.89 & 100.0 \\
\hline Dresser & 2.95 & 9.44 & 18.09 & 4.85 & 4.55 & 0.70 & 96.7 \\
\hline Fence & 2.55 & 10.32 & 5.86 & 5.77 & 3.73 & 1.34 & 100.0 \\
\hline Football & 2.28 & 5.68 & 15.06 & 6.19 & 4.55 & 1.51 & 93.1 \\
\hline Fork & 2.62 & 2.82 & 16.52 & 6.04 & 3.03 & 1.08 & 100.0 \\
\hline Frying pan & 2.05 & 3.71 & 6.35 & 5.77 & 4.32 & 0.00 & 93.1 \\
\hline Glass & 1.82 & 1.97 & 6.88 & 5.58 & 2.90 & 2.10 & 9.7 \\
\hline Glasses & 2.85 & 5.85 & 8.84 & 5.96 & 3.76 & 1.71 & 96.7 \\
\hline Glove & 3.02 & 5.38 & 9.60 & 5.81 & 3.33 & 0.70 & 90.0 \\
\hline Gun & 3.52 & 8.06 & 7.55 & 6.37 & 4.05 & 1.80 & 100.0 \\
\hline Hammer & 2.60 & 4.09 & 16.96 & 6.11 & 4.46 & 1.00 & 100.0 \\
\hline Hanger & 1.20 & 1.82 & 8.03 & 5.44 & 3.95 & 0.00 & 100.0 \\
\hline Hat & 2.35 & 3.18 & 10.86 & 6.11 & 2.90 & 1.72 & 100.0 \\
\hline Helicopter & 3.80 & 10.68 & 8.74 & 6.37 & 4.93 & 1.04 & 100.0 \\
\hline House & 3.90 & 12.82 & 4.92 & 6.48 & 2.41 & 2.68 & 100.0 \\
\hline Iron & 3.25 & 6.56 & 8.78 & 5.59 & 4.76 & 1.83 & 100.0 \\
\hline Ironing board & 2.05 & 4.79 & 5.94 & 5.89 & 5.08 & 0.00 & 100.0 \\
\hline Jacket & 3.25 & 11.18 & 16.06 & 5.48 & 3.42 & 1.53 & 53.3 \\
\hline
\end{tabular}




\begin{tabular}{|c|c|c|c|c|c|c|c|}
\hline \multicolumn{8}{|c|}{ APPENDIX B (Continued) } \\
\hline Picture & $\mathrm{COM}$ & DEC & $\mathrm{CO}$ & IMAG & AA & $\log N \mathrm{~F}$ & NA \\
\hline Kettle & 2.40 & 6.18 & 11.06 & 6.33 & 5.35 & 1.04 & 100.0 \\
\hline Key & 1.92 & 2.41 & 16.72 & 6.15 & 3.50 & 1.85 & 100.0 \\
\hline Kite & 2.85 & 5.50 & 8.27 & 6.15 & 3.74 & 0.48 & 100.0 \\
\hline Knife & 1.92 & 2.06 & 11.91 & 6.19 & 3.18 & 1.54 & 100.0 \\
\hline Ladder & 2.32 & 6.09 & 4.47 & 6.26 & 4.50 & 1.11 & 100.0 \\
\hline Lamp & 1.85 & 3.00 & 8.67 & 5.78 & 3.75 & 1.32 & 96.7 \\
\hline Lightbulb & 2.75 & 5.32 & 9.20 & 5.85 & 4.00 & 0.00 & 100.0 \\
\hline Light switch & 2.52 & 4.74 & 16.67 & 5.63 & 3.87 & 0.00 & 100.0 \\
\hline Lock & 2.22 & 3.35 & 14.67 & 4.30 & 4.89 & 1.11 & 96.7 \\
\hline Motorcycle & 4.78 & 13.82 & 12.54 & 6.44 & 4.89 & 1.08 & 100.0 \\
\hline Nail & 1.80 & 1.50 & 23.55 & 5.30 & 4.34 & 1.04 & 82.8 \\
\hline Nail file & 3.18 & 2.47 & 19.90 & 5.44 & 5.60 & 0.00 & 40.7 \\
\hline Necklace & 1.78 & 8.79 & 15.85 & 5.89 & 3.95 & 0.30 & 89.7 \\
\hline Nut & 2.30 & 3.15 & 8.36 & 5.19 & 5.50 & 0.85 & 90.0 \\
\hline Paintbrush & 2.58 & 3.41 & 15.00 & 6.15 & 4.21 & 0.00 & 100.0 \\
\hline Pants & 2.22 & 2.38 & 9.42 & 5.59 & 2.83 & 1.20 & 100.0 \\
\hline Pen & 3.15 & 5.32 & 16.11 & 6.26 & 3.35 & 1.28 & 100.0 \\
\hline Pencil & 2.32 & 3.94 & 28.99 & 6.37 & 3.28 & 1.18 & 96.7 \\
\hline Pipe & 1.88 & 3.06 & 15.12 & 5.52 & 4.53 & 1.34 & 100.0 \\
\hline Pitcher & 1.85 & 2.82 & 8.80 & 4.59 & 4.82 & 0.00 & 100.0 \\
\hline Pliers & 2.20 & 3.47 & 12.59 & 4.93 & 5.64 & 0.00 & 96.6 \\
\hline Plug & 2.25 & 5.15 & 11.88 & 5.81 & 4.55 & 0.78 & 100.0 \\
\hline Pocketbook & 2.70 & 5.59 & 6.83 & 4.83 & 4.79 & 0.00 & 86.7 \\
\hline Pot & 2.22 & 3.00 & 14.92 & 5.25 & 3.47 & 1.36 & 100.0 \\
\hline Record player & 3.32 & 7.79 & 10.56 & 5.38 & 4.43 & 0.00 & 96.7 \\
\hline Refrigerator & 2.20 & 3.35 & 6.95 & 5.67 & 3.78 & 0.90 & 100.0 \\
\hline Ring & 2.55 & 2.26 & 11.88 & 5.58 & 3.74 & 1.65 & 96.0 \\
\hline Rocking chair & 3.58 & 14.71 & 8.27 & 5.88 & 4.28 & 0.00 & 86.7 \\
\hline Rollerskate & 4.08 & 9.56 & 7.67 & 5.46 & 4.61 & 0.00 & 100.0 \\
\hline Rolling pin & 1.52 & 3.06 & 10.23 & 5.13 & 4.68 & 0.00 & 100.0 \\
\hline Ruler & 1.85 & 3.06 & 11.94 & 5.71 & 4.30 & 0.90 & 100.0 \\
\hline Sailboat & 3.58 & 6.09 & 8.60 & 5.83 & 4.68 & 0.00 & 93.1 \\
\hline Saltshaker & 3.00 & 3.82 & 14.73 & 4.71 & 4.83 & 0.00 & 86.7 \\
\hline Saw & 2.25 & 4.18 & 7.32 & 5.96 & 4.40 & 1.99 & 100.0 \\
\hline Scissors & 2.15 & 3.76 & 12.19 & 6.42 & 3.79 & 0.60 & 100.0 \\
\hline Screw & 3.25 & 2.76 & 21.34 & 6.04 & 4.93 & 0.90 & 96.6 \\
\hline Screwdriver & 2.35 & 3.24 & 27.27 & 6.25 & 5.24 & 0.48 & 100.0 \\
\hline Shirt & 3.08 & 7.56 & 15.28 & 5.92 & 3.00 & 1.65 & 86.7 \\
\hline Shoe & 3.38 & 5.09 & 10.22 & 8.67 & 2.72 & 1.15 & 100.0 \\
\hline Skirt & 1.40 & 1.85 & 12.88 & 6.04 & 3.84 & 1.30 & 93.1 \\
\hline Sled & 3.05 & 5.50 & 12.73 & 4.00 & 4.68 & 0.00 & 100.0 \\
\hline Sock & 1.62 & 3.59 & 10.05 & 6.04 & 2.44 & 0.48 & 100.0 \\
\hline Spool of thread & 3.18 & 3.18 & 12.41 & 3.88 & 4.68 & 0.48 & 76.7 \\
\hline Spoon & 2.02 & 1.47 & 17.01 & 6.17 & 2.45 & 1.04 & 100.0 \\
\hline Stool & 2.32 & 7.65 & 9.23 & 5.33 & 4.26 & 0.95 & 92.9 \\
\hline Stove & 4.02 & 12.03 & 11.24 & 5.42 & 4.18 & 1.20 & 96.7 \\
\hline Suitcase & 3.60 & 5.32 & 13.20 & 6.29 & 4.45 & 1.08 & 90.0 \\
\hline Sweater & 2.90 & 5.12 & 10.40 & 5.83 & 3.45 & 1.04 & 100.0 \\
\hline Swing & 2.72 & 4.79 & 6.81 & 5.42 & 2.98 & 1.26 & 100.0 \\
\hline Table & 1.72 & 5.47 & 9.90 & 6.00 & 2.58 & 2.31 & 96.7 \\
\hline Telephone & 3.52 & 8.09 & 8.11 & 6.38 & 3.03 & 1.99 & 100.0 \\
\hline Television & 3.22 & 6.74 & 14.28 & 6.33 & 3.08 & 2.05 & 100.0 \\
\hline Thimble & 3.35 & 2.26 & 13.68 & 5.70 & 5.92 & 0.00 & 93.1 \\
\hline Tie & 2.90 & 2.79 & 6.21 & 5.59 & 4.42 & 1.36 & 100.0 \\
\hline Toaster & 2.78 & 5.68 & 12.98 & 6.00 & 4.58 & 0.00 & 96.6 \\
\hline Toothbrush & 2.42 & 2.24 & 16.04 & 6.48 & 3.00 & 0.30 & 89.7 \\
\hline Top & 2.65 & 3.85 & 12.14 & 3.74 & 3.95 & 2.37 & 96.0 \\
\hline Train & 4.32 & 10.91 & 11.11 & 6.44 & 3.45 & 1.85 & 100.0 \\
\hline Truck & 2.75 & 7.03 & 11.71 & 5.59 & 3.08 & 1.40 & 96.7 \\
\hline Umbrella & 3.00 & 4.59 & 12.97 & 6.33 & 3.80 & 1.04 & 100.0 \\
\hline Vase & 3.15 & 2.32 & 9.48 & 5.96 & 4.87 & 0.60 & 100.0 \\
\hline Vest & 2.60 & 5.62 & 15.29 & 5.41 & 4.93 & 0.70 & 96.4 \\
\hline Wagon & 3.35 & 7.32 & 7.01 & 5.26 & 3.18 & 0.90 & 31.6 \\
\hline Watch & 3.40 & 6.41 & 9.33 & 5.89 & 4.27 & 1.74 & 100.0 \\
\hline Watering can & 2.78 & 5.62 & 12.34 & 5.41 & 4.74 & 0.00 & 96.4 \\
\hline Well & 3.82 & 7.85 & 11.62 & 5.22 & - & 3.13 & 100.0 \\
\hline Whistle & 2.55 & 3.68 & 9.86 & 5.19 & 4.68 & 0.90 & 96.6 \\
\hline Windmill & 4.20 & 7.15 & 5.20 & 5.81 & - & 0.85 & 100.0 \\
\hline Window & 3.18 & 8.24 & 8.68 & 6.11 & 3.00 & 2.12 & 95.0 \\
\hline Wine glass & 1.85 & 3.06 & 10.04 & 6.26 & 5.79 & 0.00 & 73.3 \\
\hline Wrench & 2.02 & 2.09 & 32.41 & 3.81 & 5.63 & 0.48 & 96.6 \\
\hline
\end{tabular}




\begin{tabular}{|c|c|c|c|c|}
\hline \multicolumn{5}{|c|}{ APPENDIX C } \\
\hline \multicolumn{5}{|c|}{$\begin{array}{c}\text { Table C1 } \\
\text { Values of } R \text { s, Beta Coefficients, and Squared } t \text { Ratios (for Significant Predictors, in } \\
\text { Parentheses) for Living Things for All Variables Associated With Naming-Without- } \\
\text { Deadline Response Times (RTs) and With Visual-Semantic, Pure Semantic, and } \\
\text { Pure Visual Errors in Naming With Deadline }\end{array}$} \\
\hline \multirow[b]{2}{*}{ Variable } & \multirow[b]{2}{*}{ RT } & \multicolumn{3}{|c|}{ Error Type } \\
\hline & & Visual-Semantic & Semantic & Visual \\
\hline Complexity & $+.32 *(4.92)$ & $+.36^{*}(4.77)$ & -.16 & -.10 \\
\hline Decomposability & $-.26^{\dagger}(3.80)$ & -.12 & +.07 & -.17 \\
\hline Contour overlap & $+.24^{*}(5.56)$ & $+.33^{* *}(7.58)$ & +.21 & +.09 \\
\hline Imageability & $-.38^{* * *}(11.97)$ & -.14 & +.04 & $-.26^{*}(4.50)$ \\
\hline Age of acquisition & +.19 & +.05 & +.07 & +.24 \\
\hline Name frequency $(\log )$ & +.02 & -.06 & -.14 & -.03 \\
\hline Multiple $R^{2}$ & .41 & .22 & .11 & .25 \\
\hline$F$ value & 7.44 & 2.93 & 1.27 & 3.52 \\
\hline Significance $(p)$ & $<.0005$ & $<.05$ & n.s. & $<.005$ \\
\hline
\end{tabular}

${ }^{\dagger} p=.06 . \quad{ }^{*} p<.05 .{ }^{* *} p<.01 . \quad{ }^{* * *} p<.005$.

Table C2

Values of $R \mathrm{~s}$, Beta Coefficients, and Squared $\boldsymbol{t}$ Ratios (for Significant Predictors, in Parentheses) for Nonliving Things for All Variables Associated With Naming-Without-Deadline Response Times (RTs) and With Visual-Semantic, Pure Semantic, and Pure Visual Errors in Naming With Deadline

\begin{tabular}{lcccc}
\hline & & \multicolumn{3}{c}{ Error Type } \\
\cline { 2 - 4 } \multicolumn{1}{c}{ Variable } & \multicolumn{1}{c}{$\mathrm{RT}$} & Visual-Semantic & Semantic & Visual \\
\hline Complexity & +.15 & +.04 & -.14 & +.17 \\
Decomposability & +.04 & +.02 & +.07 & -.12 \\
Contour overlap & +.12 & -.01 & -.01 & +.06 \\
Imageability & $-.22^{* *}(7.56)$ & -.01 & $+.18^{\dagger}(3.60)$ & +.03 \\
Age of acquisition & $+.21^{*}(5.15)$ & +.15 & $+.21^{\dagger}(3.66)$ & $+.24^{*}(4.95)$ \\
Name frequency $(\log )$ & $-.20^{*}(4.88)$ & .00 & -.09 & +.00 \\
$\quad$ Multiple $R^{2}$ & .29 & .28 & .07 & .09 \\
$F$ value & 8.66 & .60 & 1.61 & 2.19 \\
Significance $(p)$ & $<.0005$ & n.s. & n.s. & $<.05$ \\
\hline
\end{tabular}

${ }^{\dagger} p \leq .06 .{ }^{*} p<.05 .{ }^{* *} p<.01$.

\section{APPENDIX D}

We established the baseline probabilities for the main error types (i.e., visual-semantic, pure semantic, and pure visual errors) in terms of the amount of information making up each object concept. For instance, it may have been the case that there was a greater number of visual-semantic errors to living things solely because their semantics depends more heavily on visual features, rather than on other kinds of feature, such as how things are used, where they are located, and so on.

To address this question, we adopted the following procedure. McRae et al. (2005) provide production frequency norms for 541 living and nonliving things derived from approximately 725 participants. These norms include the number of features produced by each participant for each object, which can be classified into 1 of 10 knowledge types derived from Cree and McRae (2003). Three knowledge types correspond to visual information (i.e., visual-motion, visual-parts and surface properties, and visual-color). Other knowledge types correspond to function, sound, taste, smell, tactile, encyclopedic, and taxonomic information. There was a total of 164 items for which we could use these measures (44 animals, 22 fruit and vegetables, and 98 nonliving things). We therefore first used these norms to establish whether the living/nonliving or animal/fruit-and-vegetable categories used in our study differed in terms of the number of these features present in the object concept.

As can be seen from Table D1, both for living versus nonliving things and for animals versus fruit and vegetables, $t$ tests showed that there were clear category differences for a number of different features. We then partialled out statistically these feature differences from our analyses of task and category differences in performance, by including the number of each kind of feature produced to each object concept as covariates (we included only features that had shown significant category differences). The main findings were unchanged, despite the reduced power with fewer items. We report the least squares means (which are adjusted for the covariates) in Table D2 for living and nonliving things and in Table D3 for animals, fruit and vegetables, and nonliving things (full summary statistics for the ANCOVAs are available upon request). We conclude that there were baseline category differences for particular object features; however, the category effects we observed were present over and above these feature differences. 
APPENDIX D (Continued)

Table D1

Number of Features Taken From McRae, Cree, Seidenberg, and McNorgan (2005) for the Nine Knowledge Types of Cree and McRae (2003) for Animals Versus Fruit and Vegetables (F/V) and for All Living Versus Nonliving Things

\begin{tabular}{lllcc}
\hline \multicolumn{1}{c}{ Knowledge Type } & Animals & F/V & All Living & Nonliving \\
\hline Visual-motion & $2.20^{* *}$ & 0.00 & $1.47^{* *}$ & 0.20 \\
Visual-parts and surface properties & $5.25^{* *}$ & 3.36 & $4.62^{*}$ & 5.52 \\
Visual-color & 1.36 & 1.73 & $1.48^{* *}$ & 0.55 \\
Function & $1.00^{* *}$ & 2.91 & $1.64^{* *}$ & 3.74 \\
Sound & $0.43^{*}$ & 0.00 & 0.29 & 0.20 \\
Taste & $0.00^{* *}$ & 1.18 & $0.39^{* *}$ & 0.00 \\
Smell & 0.07 & 0.05 & 0.06 & 0.07 \\
Tactile & $0.25^{* *}$ & 1.00 & 0.50 & 0.37 \\
Encyclopedic & 3.77 & 3.41 & $3.65^{* *}$ & 2.39 \\
Taxonomic & $2.39^{*}$ & 1.55 & $2.11^{* *}$ & 0.89 \\
\hline
\end{tabular}

Note-Comparison of animals versus fruit and vegetables or living versus nonliving things. ${ }^{*} p<.01 . \quad{ }^{* *} p<.005$.

Table D2

Least Squares Means for Living and Nonliving Things in Naming Without Deadline and Naming With Deadline, for Visual-Semantic, Pure Semantic, and Pure Visual Errors

\begin{tabular}{lccccc}
\hline & \multicolumn{2}{c}{ Naming Without Deadline } & & \multicolumn{2}{c}{ Naming With Deadline } \\
\cline { 2 - 5 } \multicolumn{1}{c}{ Error Type } & Living & Nonliving & & Living & Nonliving \\
\hline Visual-semantic & 6.74 & 0.56 & & 12.28 & 1.05 \\
Pure semantic & 0.09 & 0.21 & -0.01 & 2.49 \\
Pure visual & 0.01 & 0.54 & 0.38 & 1.44 \\
\hline
\end{tabular}

Table D3

Least Squares Means for Animals, Fruit and Vegetables (F/V), and Nonliving Things in Naming Without Deadline and Naming With Deadline, for Visual-Semantic, Pure Semantic, and Pure Visual Errors

\begin{tabular}{|c|c|c|c|c|c|c|}
\hline \multirow[b]{2}{*}{ Error Type } & \multicolumn{3}{|c|}{ Naming Without Deadline } & \multicolumn{3}{|c|}{ Naming With Deadline } \\
\hline & Animals & $\mathrm{F} / \mathrm{V}$ & Nonliving & Animals & $\mathrm{F} / \mathrm{V}$ & Nonliving \\
\hline Visual-semantic & 9.45 & 2.52 & 0.29 & 15.64 & 7.49 & 0.62 \\
\hline Pure semantic & 0.19 & 0.03 & 0.18 & 0.36 & -0.59 & 2.45 \\
\hline Pure visual & -0.05 & 0.17 & 0.53 & 0.30 & 0.78 & 1.39 \\
\hline
\end{tabular}

(Manuscript received October 27, 2005; revision accepted for publication March 20, 2006.) 